\title{
Study of design methodologies of steel column bases
}

\section{Estudo de metodologias para o dimensionamento de bases de pilares de aço}
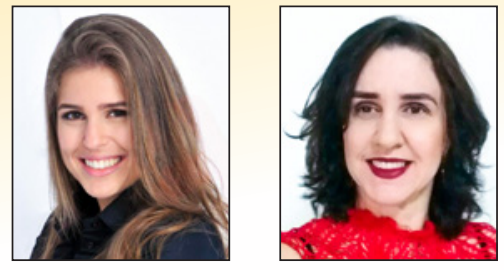

I. PIANA a

piana.iza@gmail.com

A. F. G. CALENZANI afcalenzani@gmail.com

\begin{abstract}
The behavior of a steel structure is directly related to the type of base used in the columns, which is essential to the stability and security of the structural system. The Brazilian standard ABNT NBR 8800:2008 does not directly covers this subject. Another Brazilian standard, ABNT NBR 16239:2013, presents a limited design procedure to hollow columns. In this paper, two design methodologies are presented considering the uniform and triangular pressure distribution between the base plate and the concrete surface. A computational program has been developed to design steel column bases considering both methodologies mentioned. The program has been validated with manually solved design examples and conclusions about the pressure distribution design procedures were made from the 200 bases designed by the program. It was noted that, for the triangular pressure distribution, there is an interval in which the procedure is not completely applicable. Apart from this interval, there was no significant difference in the results.
\end{abstract}

Keywords: steel column base plates, design methodologies, computational program.

\section{Resumo}

O comportamento de uma estrutura em aço está diretamente relacionado ao tipo de base utilizada nos pilares, sendo esta essencial à estabilidade e segurança do sistema estrutural. A ABNT NBR 8800:2008 não aborda diretamente esse assunto e a ABNT NBR 16239:2013 apresenta formulações somente para bases de pilares tubulares. Neste trabalho, são apresentadas duas metodologias para o dimensionamento de bases de pilares que consideram as hipóteses de distribuição de tensões de contato uniforme e linear entre a placa de base e o concreto. Um programa computacional foi desenvolvido para dimensionar bases de pilares de aço considerando essas duas hipóteses. O programa foi validado com exemplos resolvidos manualmente e 200 bases foram dimensionadas para análise das metodologias. Foi detectada a existência de um intervalo para o qual a metodologia que considera a distribuição linear de tensões não é apropriada. Fora deste intervalo, observou-se pouca divergência entre os resultados.

Palavras-chave: bases de pilares de aço, metodologias para o dimensionamento, programa computacional.

Centro Tecnológico, Universidade Federal do Espírito Santo, Vitória, ES, Brasil. 


\section{Introduction}

Column bases are used as a steel-concrete interface between steel columns and their foundations. Their main function is to transmit the structure stresses to the concrete footing surface and to link the column bottom end to the footing. Column bases include base plates, anchor rods and shear resistant elements such that shear lugs, Figure 1.

Steel connections are extremely important to steel structures. The connections are the ones who are ensuring the structure stability and must realize the best possible way the type of internal link considered in the design. Brazilian standard ABNT NBR 8800:2008 [1] does not directly cover steel column base connections and takes the reader to the design guide by Fisher and Kloiber [2]. Another Brazilian standard, ABNT NBR 16239:2013 [3], includes this subject, although it is limited to hollow steel column bases. Other writers, such as Bellei [4] and Baião Filho and Silva [5] do not present the stress case of combined tensile axial loads and moment. Additionally, most texts about this kind of connection consider a triangular pressure distribution between the concrete and the base plate. ABNT NBR 16239:2013[3], however, considers a uniform pressure distribution. Therefore, scientific literature lacks more research articles on the design of steel column bases according to

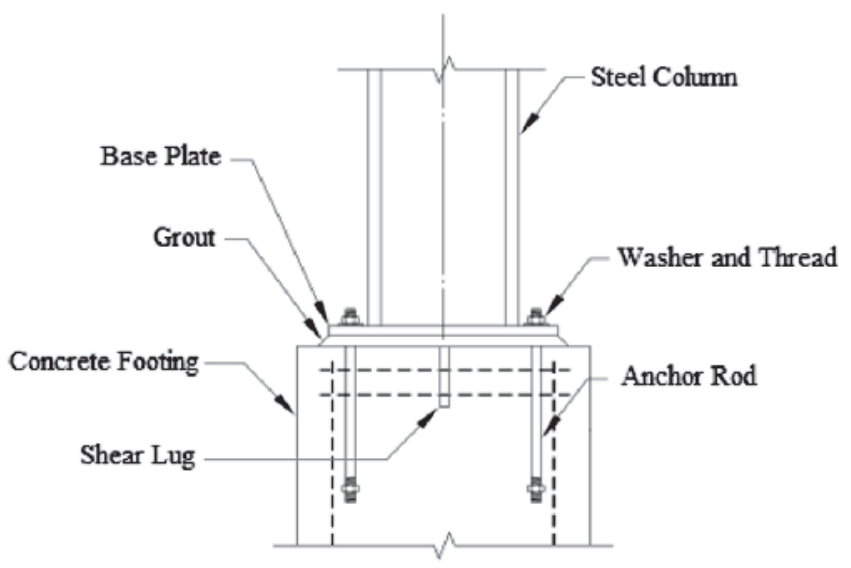

Figure 1

Components of a steel column base

Adapted: Fisher and Kloiber [2]

the newer Brazilian technical guides, the NBRs, and that present a more complete content about the requiring strengths at the plates. This study had as a goal to automate the design of steel column bases following Brazilian technical standards, considering both

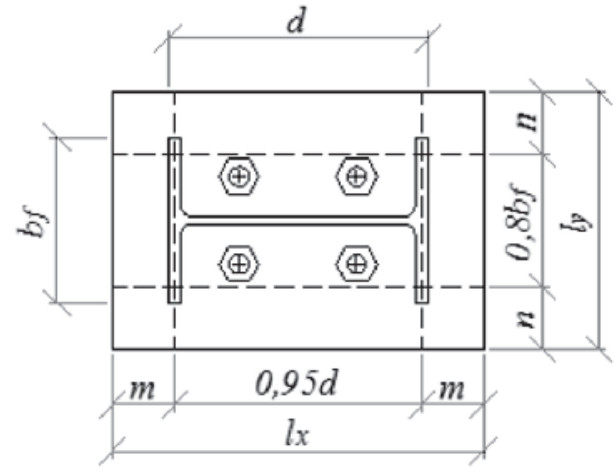

(a) Pinned W-shape Column Base

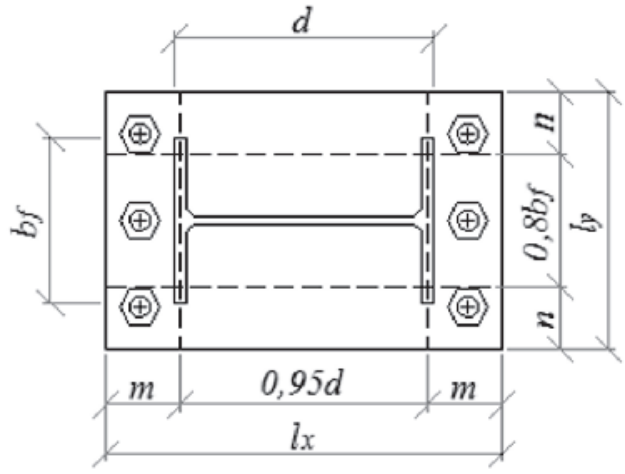

(b) Fixed W-shape Column Base

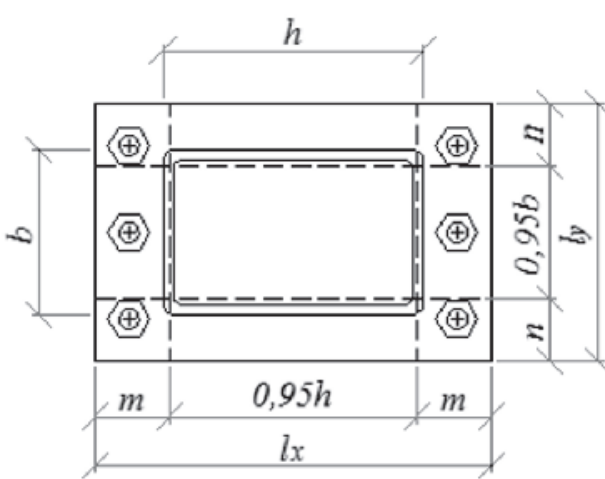

(c) Rectangular Hollow Column Base

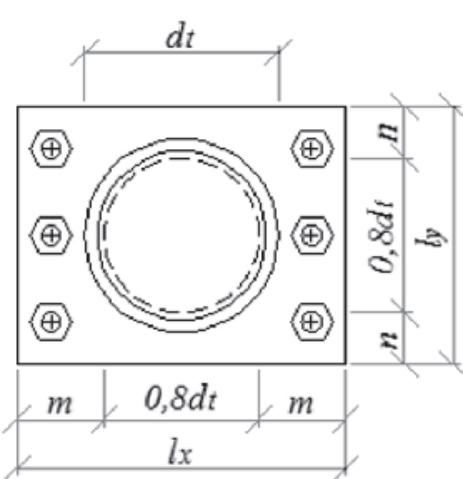

(d) Circular Hollow Column with Rectangular Plate base

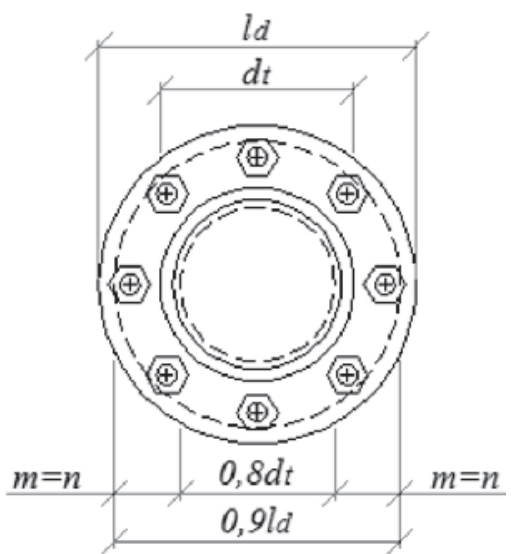

(e) Circular Hollow Column with Circular Plate Base

Figure 2

Types of steel column bases 
triangular and uniform pressure distribution. Additionally, the designs of column bases considering triangular and uniform pressure distributions were compared.

Five different types of steel column bases were considered: pinned W-shape column bases with no moment transferred to the footing (Figure 2a); fixed $\mathrm{W}$-shape column bases with moment transferred to the footing (Figure 2b); rectangular hollow column (Figure 2c); circular hollow column bases with rectangular base plate (Figure 2d); circular hollow column bases with circular base plates (Figure 2e).

Usually, column bases are subject to compression or tensile forces, flexural moment and shear forces that can induce the followings limit states: crushing of the concrete in contact with the base plate, formation of a plastic hinge mechanism in the base plate, yielding of the anchor rod in tension, sliding of the base, anchor rod concrete pullout, among others that will not be covered in this text. For the base design of a W-shape column, the procedure presented in this text is based on the Design Guide of Fisher and Kloiber [2], since ABNT NBR 8800:2008 [1] does not present a design procedure for column base plates. For the base design of hollow columns, the procedure presented is this text can be found in ABNT NBR 16239:2013 [3].

\section{Steel column base plate design}

\subsection{Design of base plates subject to axial forces}

To accommodate the elements of a base, such as anchor rods and the column, the base plate minimum dimensions are calculated taking in count column dimensions and the minimum distances for the anchor rods, such as the hole center distance to the edge of the plate and the hole to hole distance.

\subsubsection{Base plates subject to compression forces}

The design strength of the concrete in a base plate subject to compression axial force is given by equation (1).

$\sigma_{c, R d}=\frac{f_{c k}}{\gamma_{c} \gamma_{n}} \sqrt{\frac{A_{2}}{A_{1}}} \leq f_{c k}$

Where $f_{c k}$ is the compressive strength of concrete, $\gamma_{n}$ is a behavior factor equal to $1.40, \gamma_{c}$ is the resistance factor, $A_{1}$ is the base plate area and $A_{2}$ is the maximum area of the portion of the supporting surface that is geometrically similar to and concentric with the loaded area. The design strength of the concrete can be increased by $\sqrt{A_{2} / A_{1}}$ when the concrete surface is larger than the plate area and the effects of the concrete confinement can be considered. However, this increase hits a maximum value when $A_{2} \geq 4 A_{1}$. Considering the contact stresses between the plate and the concrete surface as uniformly distributed, the minimum area of a base plate can be determined as equation (2).

$A_{1, \min }=\frac{N_{S d} \gamma_{c} \gamma_{n}}{f_{c k}} \sqrt{\frac{A_{1}}{A_{2}}} \leq \frac{N_{S d} \gamma_{c} \gamma_{n}}{2 f_{c k}}$

Where $N_{s d}$ is the acting compression force. The base plate is treated as a console for the definition of its thickness. The base plate must have sufficient thickness to resist bending at the assumed critical sections shown in Figure 2 (distances $m$ and $n$ ) and, in W-shape column bases, additionally in the area between the column flanges (distance $\lambda n^{\prime}$ ). The design bending moment per unit width of the plate is:

$M_{p, S d}=\sigma_{c, S d} \frac{l_{m a ́ x}^{2}}{2}$

The variable $I_{\text {máx }}$ is the greater value between distances $m, n$ and $\lambda n^{\prime}$ (equation (4)). The factor $\lambda$ can be conservatively taken as 1 .

$\lambda n^{\prime}=\lambda \frac{\sqrt{d b_{f}}}{4}$

Utilizing the nominal bending strength per unit width as the resisting moment of the plate, the equation that determines the minimum thickness for the base plate can be found (equation (5)).

$t_{p, \text { min }}=l_{\text {máx }} \sqrt{\frac{2 \sigma_{c, S d}}{\left(f_{y} / \gamma_{a 1}\right)}}$

The variable $f_{y}$ is the yield limit of the steel and $\gamma_{a 1}$ is the strength reduction factor in bending.

\subsubsection{Base plates subject to tensile force}

In base plates subject to tensile force, the anchor rods are subject to the same intensity and cause bending moment (equation (6)) on the column web.

$M_{p, S d}=F_{t, S d}\left(\frac{g-t_{w}}{2}\right)$

The variable $g$ is the distance between anchor rods in the direction perpendicular to the column web (Figure 3 ) and $t_{w}$ is the thickness of the column web. The effective width $I_{\text {ef }}$ of the base plate to resist the existing moment can approximately be calculated utilizing a

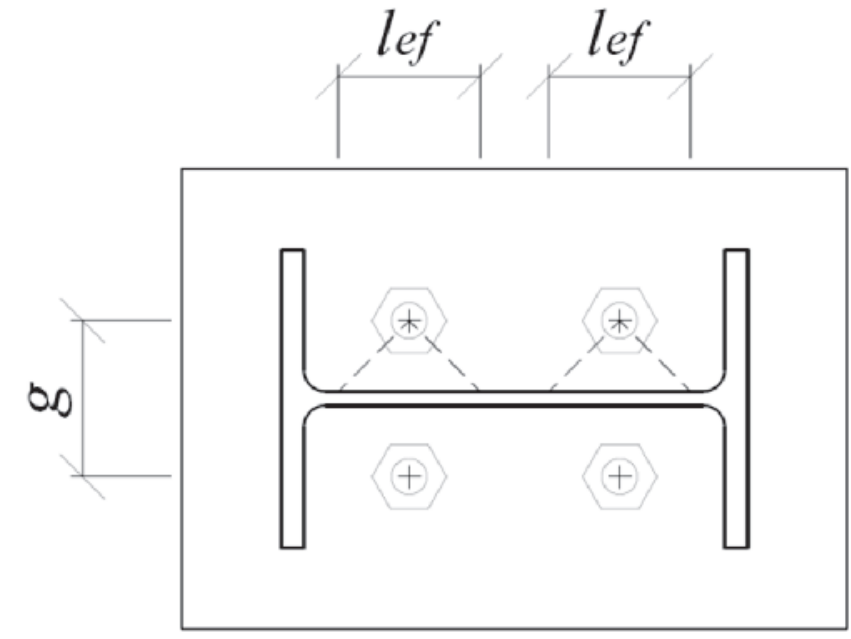

Figure 3

Effective bending width for anchor rods between the column flanges

Adapted: Fisher and Kloiber [2] 
$45^{\circ}$ distribution from the anchor rods centerline, represented by the dashed line at Figure 3, to the edge of the column web (equation (7)). The minimum thickness required for the plate can be determined by equation (8) for $\mathrm{W}$-shape columns and by equation (9) for hollow columns.

$$
\begin{aligned}
& l_{e f}=2\left(\frac{g-t_{w}}{2}\right) \\
& t_{p, \text { min }}=\sqrt{\frac{2 F_{t, S d}}{\left(f_{y} / \gamma_{a 1}\right)}} \\
& t_{p, \text { min }}=\sqrt{\frac{2 n_{b} F_{t, S d}\left(m_{e q}-a_{1}\right)}{l_{y, e q}\left(f_{y} / \gamma_{a 1}\right)}}
\end{aligned}
$$

(7) $m_{e q}=\frac{l_{d}-0.8 d_{t}}{2}$

The variable $I_{(y, e q)}$ is defined by equations (10) and (11) for hollow columns with rectangular and circular base plates, respectively.

$l_{y, e q}=n_{b}\left(d_{b}+m-a_{1}\right) \leq l_{y}$

$l_{y, e q}=n_{b}\left(d_{b}+m_{e q}-a_{1}\right) \leq 0.9 l_{d}$

(11) $e=\frac{M_{S d}}{N_{s d}}$

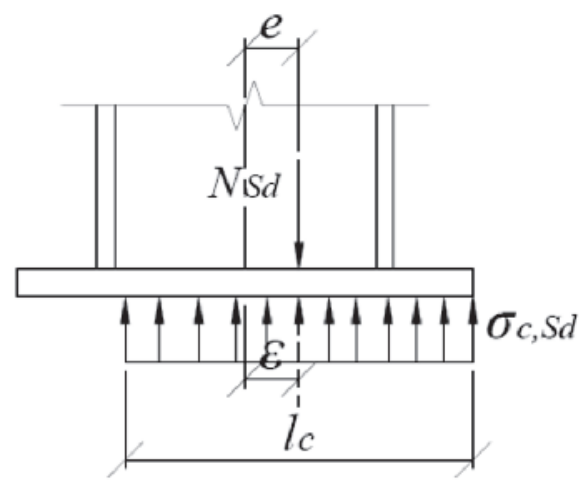

(b) Plate subject to compression with small moment

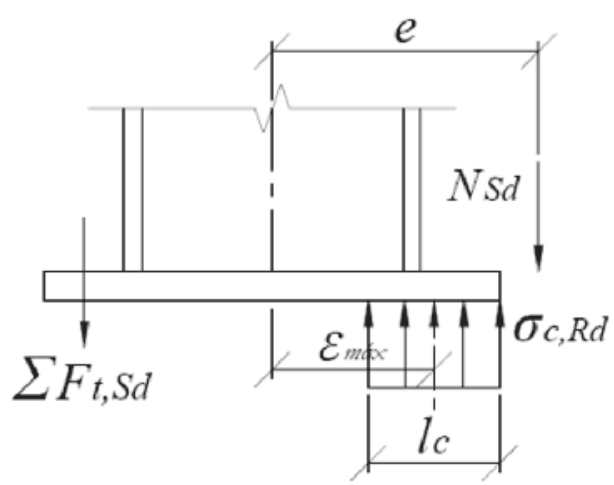

(d) Plate subject to compression with large moment

\section{Figure 4}

Behavior of plates subject to compression force and moment considering the uniform contact pressure hypothesis 


\subsubsection{Uniform bearing distribution hypothesis}

A base plate is considered subject to compression with small moA base plate is considered subject to compression with small moment when $e \leq \varepsilon_{\text {máx }}$, Figure 4(b), and by large moment when $e>\varepsilon_{\text {máx }}$, Figure $4(d), \varepsilon_{\text {máx }}$ being determined by:

$\varepsilon_{\text {máx }}=\frac{l_{x}}{2}-\frac{N_{S d}}{2 \sigma_{c, R d} l_{y}}$

\subsubsection{Base plates subject to compression force with small moment}

In base plates subject to small moment, the contact length between the plate and the concrete is determined by equation (16). When $I_{c} \geq I_{\text {máx }}$, the plate thickness is calculated by equation (17), whereas when $I_{c}<I_{\text {máx }}$, by equation (18). The stress in the plate is defined by equation (19).

$l_{c}=l_{x}-2 e$

$t_{p, \text { min }}=l_{\text {máx }} \sqrt{\frac{2 \sigma_{c, S d}}{\left(f_{y} / \gamma_{a 1}\right)}}$

$t_{p, \text { mín }}=\sqrt{\frac{4 \sigma_{c, S d} l_{c}\left(l_{\text {máx }}-l_{c} / 2\right)}{\left(f_{y} / \gamma_{a 1}\right)}}$

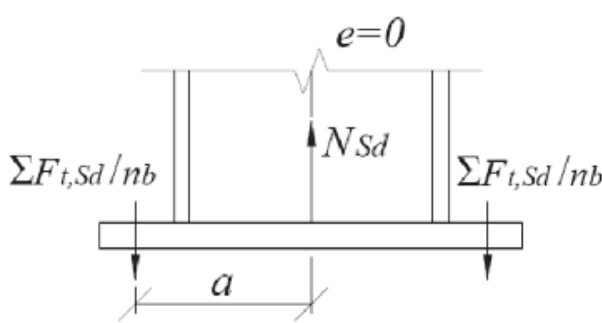

(a) Plate subject to tension

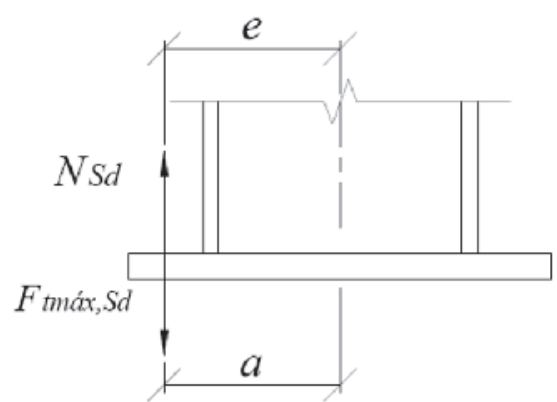

(c) Plate subject to tension with the limit moment $\sigma_{c, S d}=\frac{N_{S d}}{l_{y} l_{c}}$

\subsubsection{Base plates subject to compression force with large moment}

In base plates subject to large moment, the contact length is calculated from the summation of moments taken about the anchor rod tensile force direction (equation (20)).

$l_{c}=\left(a+\frac{l_{x}}{2}\right) \pm \sqrt{\left(a+\frac{l_{x}}{2}\right)^{2}-\frac{2 N_{c, S d}(e+a)}{\sigma_{c, R d} l_{y}}}$

The variable a being the distance from the anchor rods center to the center of the plate. The horizontal dimensions of the base plate must be increased when a real solution of equation (20) is not possible for W-shape columns, or when the conditions of equations (21) and (22) for hollow columns with rectangular and circular base plates, respectively, cannot be attended.

$\left(a+\frac{l_{x}}{2}\right)^{2} \geq \frac{2.25 N_{S d}(e+a)}{\sigma_{c, R d} l_{y}}$

$\left(a+\frac{l_{x}}{2}\right)^{2} \geq \frac{3.125 N_{S d}(e+a)}{\sigma_{c, R d} l_{y}}$

The minimum thickness can be defined the same way as for base

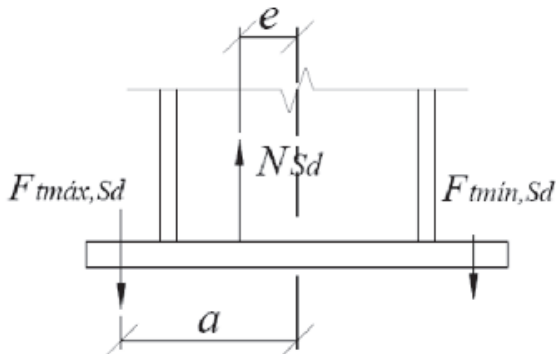

(b) Plate subject to tension with small moment

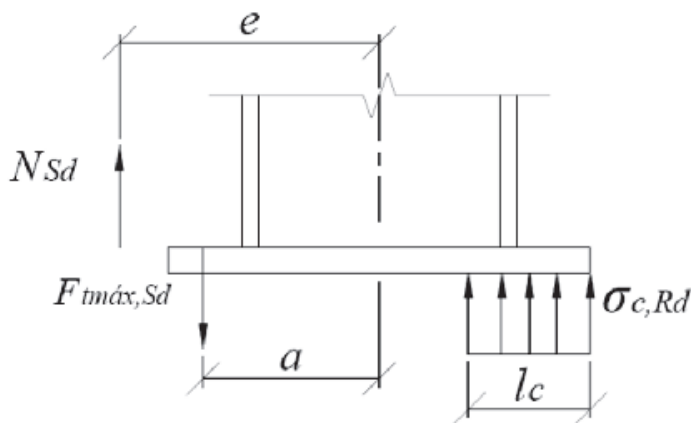

(d) Plate subject to tension with large moment

\section{Figure 5}

Behavior of plates subject to tensile force and moment considering the uniform contact pressure hypothesis 
plates subject to small moments, equations (17) and (18). However, an additional verification must be done due to the presence of the anchor rods tensile force $F_{t, S d^{\prime}}$, equation (23).

$F_{t, S d}=\frac{2\left(\sigma_{c, R d} l_{y} l_{c}-N_{S d}\right)}{n_{b, e q}}$

The equivalent number of anchor rods at the plate $n_{b, e q}$ is equal to the total number of anchor rods $n_{b}$ for W-shape columns or hollow columns with rectangular base plate. For hollow circular columns with circular plates, $n_{b, e q}$ is equal to $2 n_{b} / 3$. The minimum thickness $t_{p, \min }$ is given by equation (24).

$t_{p, \text { min }}=\sqrt{\frac{4 \sum F_{t, S d} x}{l_{y, e q}\left(f_{y} / \gamma_{a 1}\right)}}$

The length $x$ for W-shape columns is considered as the distance between the center of the anchor rod to the center of the column flange and, for hollow columns, as the distance from the center of the anchor rods to the critical section of the column. Variable $I_{y, e q}$ is equal to $I_{y}$ for W-shape columns and defined by equations (10) and (11) for hollow columns with rectangular and circular base plates, respectively.

\subsubsection{Base plates subject to tensile force with small moment}

In case of bases subject to tension with moment, it is considered that a base plate is subject to small moment when $e \leq a$, Figure $5(b)$, and by large moment when $e>a$, Figure 5(d). For plates subject to tension with small moment, the highest tensioned anchor rod force is determined by equation (25).

$F_{t, S d}=\frac{N_{S d}}{n_{b}}+\frac{M_{S d}}{a n_{b, e q}}$

The minimum thickness of the base plate must be calculated the same way as for pure tension base plates (item 2.1.2): in case of W-shape column, using equation (8) and in case of hollow columns, equation (9). However, the force in the highest tensioned anchor rods $\left(F_{t, S d}\right)$ must be determined by equation (25).

\subsubsection{Base plates subject to tensile force with large moment}

The design procedure for bases subject to tensile force with large moment is similar to the case of compression with large moment.

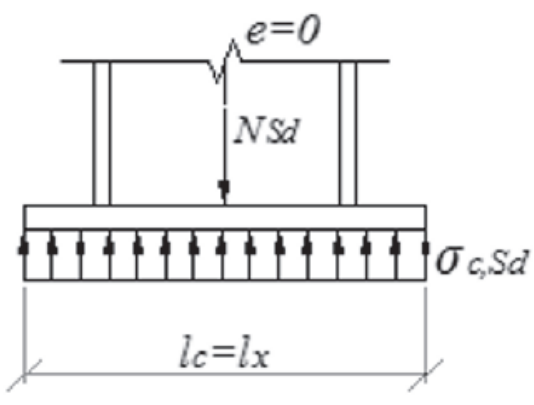

(a) Plate subject to compression

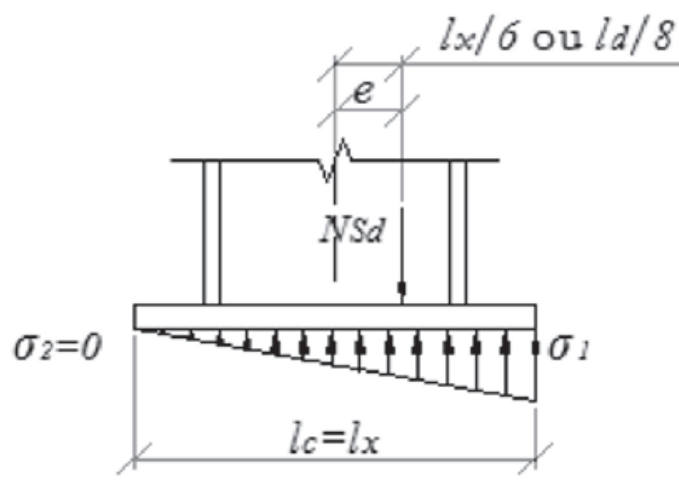

(c) Plate subject to compression with the limit moment

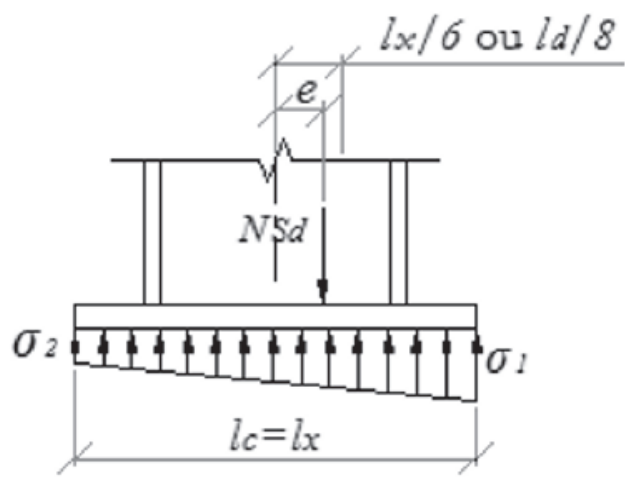

(b) Plate subject to compression with small moment

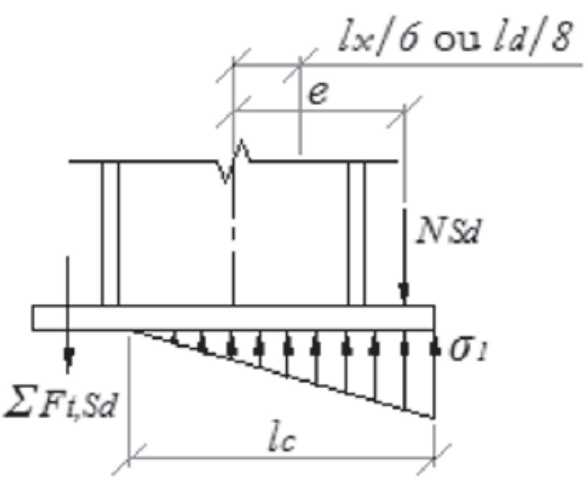

(d) Plate subject to compression with large moment

\section{Figure 6}

Behavior of plates subject to subject to compression force and moment considering the triangular contact pressure hypothesis for rectangular plates 
To calculate the length $I_{c}$, equations (20), (21) and (22) must be utilized, but the factor $(e+a)$ must be substituted for $(e-a)$. The anchor rods force $F_{t, S d}$ is given by equation (26) and the plate thickness is determined the same way as for plates subject to compression force with large moment, equations (17), (18) and (24).

$\sum F_{t, S d}=\left(\sigma_{c, R d} l_{y} l_{c}+N_{S d}\right)$

\subsubsection{Triangular contact stress distribution hypothesis}

\subsubsection{Base plates subject to compression force with small moment}

Considering a triangular contact stress distribution between the base plate and the concrete surface, the base plate is classified as compressed with small moment whether $e \leq I_{x} / 6$ for rectangular plates and $e \leq I_{d} / 8$ for circular plates (Figure 6 (b)) and as compressed with large moment whether $e>I_{x} / 6$ for rectangular plates and $e>I_{d} / 8$ for circular plates (Figure 6 (d)).

In case of plates compressed by small moment, contact pressures $\sigma_{1}$ and $\sigma_{2}$ are determined by equation (27) for rectangular plates and by equation (28) for circular plates. If $\sigma_{1}>\sigma_{c, R d}$, the plates dimensions should be redesigned.

$\sigma_{1,2}=\frac{N_{S d}}{l_{x} l_{y}} \pm \frac{6 M_{S d}}{l_{y} l_{x}^{2}}$

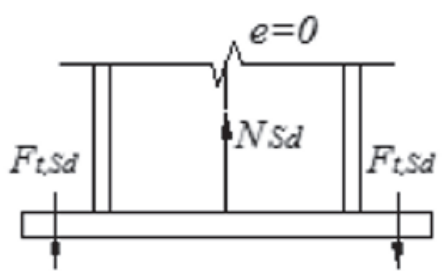

(a) Plate subject to tension

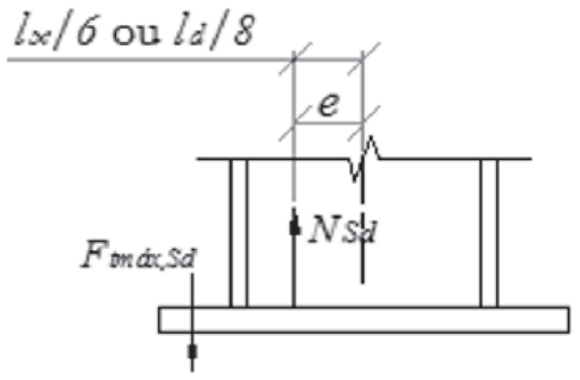

(c) Plate subject to tension with the limit moment $\sigma_{1,2}=\frac{4 N_{S d}}{\pi l_{d}^{2}} \pm \frac{32 M_{S d}}{\pi l_{d}^{3}}$

The bending moment per unit width of the plate at the critical section $m$ is defined by equation (29), where $\sigma_{m}$ is the stress in section $m$, and is given by equation (30) for rectangular plates and by equation (31) for circular base plates.

$M_{p, S d}=\sigma_{m}\left(\frac{m^{2}}{2}\right)+\left(\sigma_{1}-\sigma_{m}\right)\left(\frac{m^{2}}{3}\right)$

$\sigma_{m}=\sigma_{1}-\frac{12 M_{S d} m}{l_{y} l_{x}^{3}}$

$\sigma_{m}=\sigma_{1}\left(1-\frac{m}{l_{d}}\right)$

The bending moment per unit width of the plate at the critical section $n$ is defined by equation (32). The largest moment between equations (29) and (32) must be taken as the critical moment and be utilized in equation (33) to calculate the plate thickness.

$M_{p, S d}=\frac{N_{S d}}{l_{x} l_{y}}\left(\frac{n^{2}}{2}\right)$

$t_{p, \min }=\sqrt{\frac{4 M_{p, S d}}{l_{y, e q}\left(f_{y} / \gamma_{a 1}\right)}}$

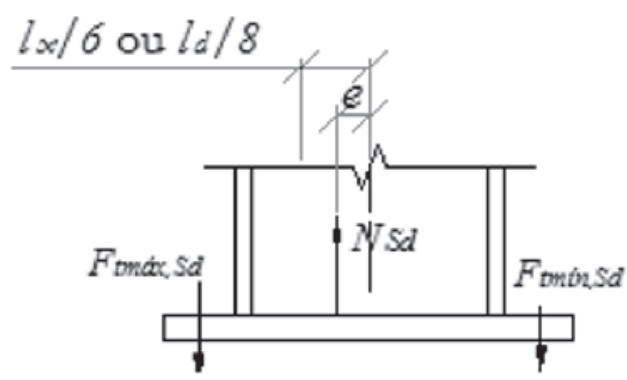

(b) Plate subject to tension with small moment

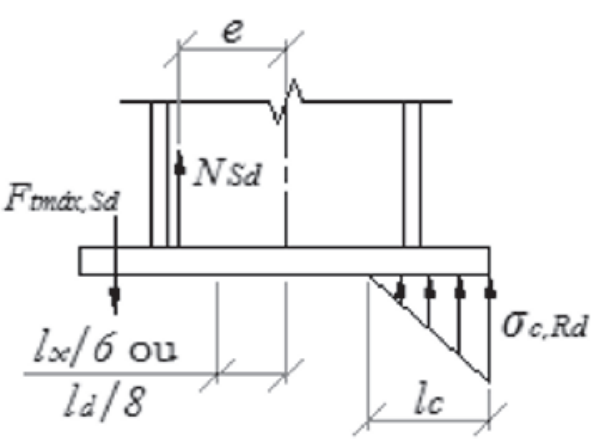

(d) Plate subject to tension with large moment

\section{Figure 7}

Behavior of plates subject to tensile force and moment considering the triangular contact pressure hypothesis for rectangular plates 


\subsubsection{Base plates subject to compression force with large moment}

In base plates compressed with large moment considering triangular contact pressure distribution, the contact length $I_{c}$ must be determined first by equation (34). In case the solution of equation (34) is not real, plate dimensions must be increased.

$$
l_{c}=\frac{3\left(a+\frac{l_{x}}{2}\right) \pm \sqrt{\left[3\left(a+\frac{l_{x}}{2}\right)\right]^{2}-\frac{24\left(N_{S d} a+M_{S d}\right)}{\sigma_{c, R d} l_{y}}}}{2}
$$

The thickness determined by equation (35) considers bending at the plate caused by contact pressure. If $I_{c} \geq I_{\text {máx }}$, the bending moment per unit width at critical section is given by equation (36), and $\sigma_{m}$ is given by equation (37). If $I_{c}<I_{\text {máx }}$ the bending moment per unit width at the critical section is determined by equation (38).

$t_{p, \min }=\sqrt{\frac{4 M_{p, S d}}{\left(f_{y} / \gamma_{a 1}\right)}}$

$M_{p, S d}=\frac{\sigma_{m} l_{m a ́ x}^{2}}{2}+\frac{\left(\sigma_{c, R d}-\sigma_{m}\right) l_{m a ́ x}^{2}}{3}$

$\sigma_{m}=\frac{\sigma_{c, R d}\left(l_{c}-l_{\text {máx }}\right)}{\sigma_{c, R d} l_{\epsilon}\left(l_{m a x}\right.}$

$M_{p, S d}=\frac{\sigma_{c, R d} l_{\mathcal{E}}}{2}\left(l_{\text {máx }}-\frac{l_{c}}{3}\right)$

Additionally, the minimum thickness necessary for the plate to resist bending moment caused by anchor rods at the critical section of the column must be calculated. The summation of tensile forces $\sum F_{(t, S d)}$ of the anchor rods that are required at the plate is given by equation (39)

$\sum F_{t, S d}=\frac{\sigma_{c, R d} l_{c} l_{y}}{2}-N_{s d}$

The force per anchor rod is equal to the summation of tensile forces divided by half of the equivalent number of anchor rods at the plate. Plate thickness is determined in the same way as for compressed plates with large moment considering a uniform bearing pressure distribution (equation (24), item 2.2.1.2).

\subsubsection{Base plates subject to tensile force with small moment}

For bases subject to tensile force, it is considered that a plate is subject to small moment (Figure 7(b)) if $e \leq I_{x} / 6$ for rectangular plates and $e \leq I_{d} / 8$ for circular plates and subject to large moment (Figure $7(d)$ ) when $e>I_{x} / 6$ or $e>I_{d} / 8$ for rectangular and circular base plates, respectively.

Observing Figure 7(b) and Figure 5(b) which illustrate base plates subject to tensile force with small moment considering triangular and uniform contact pressure distribution, respectively, it is noticeable that there is a similar stress situation. Therefore, the same design procedure is considered to determine tensile force at the anchor rods (equation (25)) and thickness (equation (8) for Wshape column and equation (9) for hollow columns).

\subsubsection{Base plates subject to tensile force with large moment}

It is noticed in Figures $6(\mathrm{~d})$ and $7(\mathrm{~d})$ the similarity of the stress configuration at plates subject to compression or tensile force with large moment. In both cases, there is tensile force at the anchor rods in just one side of the plate and there is contact pressure between the plate and the concrete surface with stress equal to concrete compression strength. Therefore, the design procedure is similar to the case in which the base is subject to compression with large moment, except by the contact length $I_{c}$ that can be determined by equation (40) and by the anchor rods tensile force that is given by equation (41).

$l_{c}=\frac{3\left(a+\frac{l_{x}}{2}\right) \pm \sqrt{\left[3\left(a+\frac{l_{x}}{2}\right)\right]^{2}-\frac{24\left(M_{S d}-N_{S d} a\right)}{\sigma_{c, R d} l_{y}}}}{2}$

$\sum F_{t, S d}=\frac{\sigma_{c, R d} l_{c} l_{y}}{2}+N_{s d}$

\subsection{Design of base plate subject to shear force}

The most common means of transferring shear force $\left(V_{S_{d}}\right)$ from column base plates to concrete are: friction, shear lugs and anchor rods. The Brazilian standard ABNT NBR 16239:2013 [3] determines the concrete shear strength $\tau_{c, R d}$ as showed in equation (42).

$\tau_{c, R d}=0.2 \frac{f_{c k}}{\gamma_{c}} \leq 4 M P a$

The resisting friction force $V_{a t, R d}$ at a base plate is determined by equation (43). The friction coefficient $\mu$ is considered equal to 0.90 for base plates inside the concrete, 0.70 for plates upon concrete surface and 0.55 for plate on grout. In case friction is not enough to totally resist the horizontal forces, another method must be utilized for transferring shear.

$V_{a t, R d}=\mu \sigma_{c, S d} l_{c} l_{y} \leq \tau_{c, R d} l_{x} l_{y}$

\subsection{Design of anchor bolt}

The resisting tensile force $F_{t, R d}$ of an anchor rod is given by equation (44), where $f_{u b}$ is the tensile strength of the anchor rod material, $A_{b}$ is the full section area of an anchor rod and $\gamma_{a 2}$ is the resistance factor. The diameter $d_{b}$ of the contributing anchor rod is determined by equation (45).

$F_{t, R d}=0.75 \frac{f_{u b} A_{b}}{\gamma_{a 2}}$

$d_{b, \min }=1.3 \sqrt{\frac{F_{t, S d}}{\left(f_{u b} / \gamma_{a 2}\right)}}$

The shear force acting in each anchor rod is given by equation (46). The number of anchor rods for shear $n_{v}$ must be considered as half the number of anchor rods at the plate or, in case of plate washer welded to the plate between the anchor rod nut and the top 
of the base plate, as the total number of anchor rods at the plate. The resistant shear force $F_{v, R d}$ of an anchor rod is given by equation (47). The necessary diameter $d_{b}$ to resist shear is determined by equation (48).

$F_{v, S d}=\frac{V_{S d}}{n_{v}}$

$F_{v, R d}=0.4 \frac{f_{u b} A_{b}}{\gamma_{a 2}}$

$d_{b, \min }=1.76 \sqrt{\frac{F_{v, S d}}{\left(f_{u b} / \gamma_{a 2}\right)}}$

Anchor rods subject to combined effect of tensile and shear forces must obey equation (49).

$\left(\frac{F_{t, S d}}{F_{t, R d}}\right)^{2}+\left(\frac{F_{v, S d}}{F_{v, R d}}\right)^{2} \leq 1$

\subsection{Design of shear lugs}

Shear stress transference between column and base occurs at the area in which the shear lug is bearing on concrete. The resistant shear force $V_{b c, R d}$ given by the shear lug is determined by equation (50). The symbols are illustrated at Figure 8 . The minimum plate area $\left(A_{b c, \min }=b_{v} b_{h}\right)$ is given by equation (51).

$V_{b c, R d}=\sigma_{c, R d}\left(b_{v}-e_{n}\right) b_{h}$

$A_{b c, \min }=\frac{V_{S d}}{\sigma_{c, R d}}$

The minimum thickness for the shear lug is determined by equation (52). To prevent bending at the base plate due to the shear lug, it is highly recommended for the plate to have a larger or equal thickness than the shear lug $\left(t_{b c, \text { min }} \leq t_{p, \text { min }}\right)$.

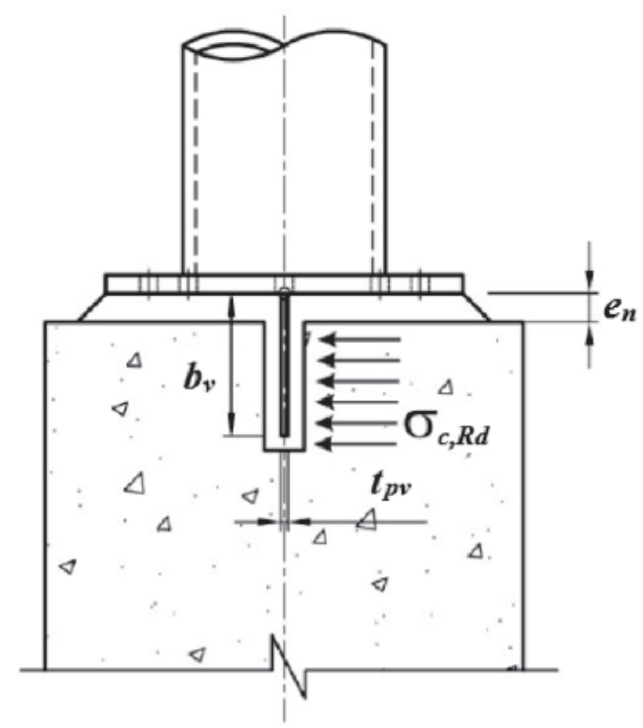

Figure 8

Steel base plate with shear lug $t_{b c, \text { min }}=\sqrt{\frac{2 V_{S d}\left(b_{v}+e_{n}\right)}{b_{h}\left(f_{y} / \gamma_{a 1}\right)}}$

\section{Methodology}

\subsection{Computational implementation}

To ease computational implementation, eight flowcharts were developed. One flowchart illustrates the software structure and the others, the bases design: tensile, compression, compression with small moment, tensile with small moment, compression or tensile with large moment, shear and a flowchart about anchor rods design. The goal was to present the sequence and the order of the main equations necessary to the development of the software. For instance, Figure 9 presents the flowchart of tension subject bases with small moment.

The design flowcharts were implemented using Visual Basic [6] language. The tool used for the software development was chosen by the easiness of the interface making procedure, code implementation, and error debugging. Besides that, it was intended to provide to the academic and professional communities a software tool of easy access and comprehension.

\subsection{About the software developed}

The developed software, named BASE, designs base plate, anchor rods and their locations at the plate, shear lug and minimum dimensions for the concrete element that is going to receive the steel column. The developed software makes possible the consideration of both uniform and triangular bearing pressure hypotheses and considers the following stress cases at the plate: tensile, compression, tension with moment and compression with moment. Additionally, the software includes the design of shear strenghtening elements.

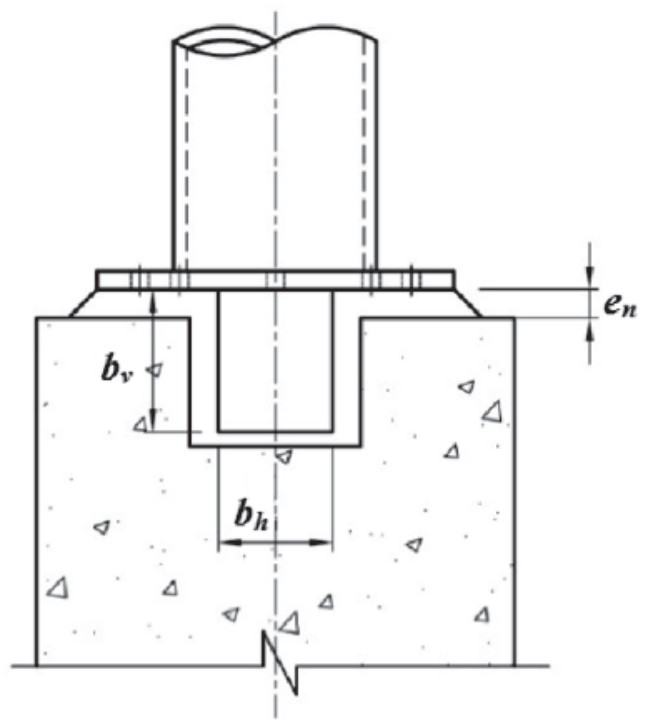




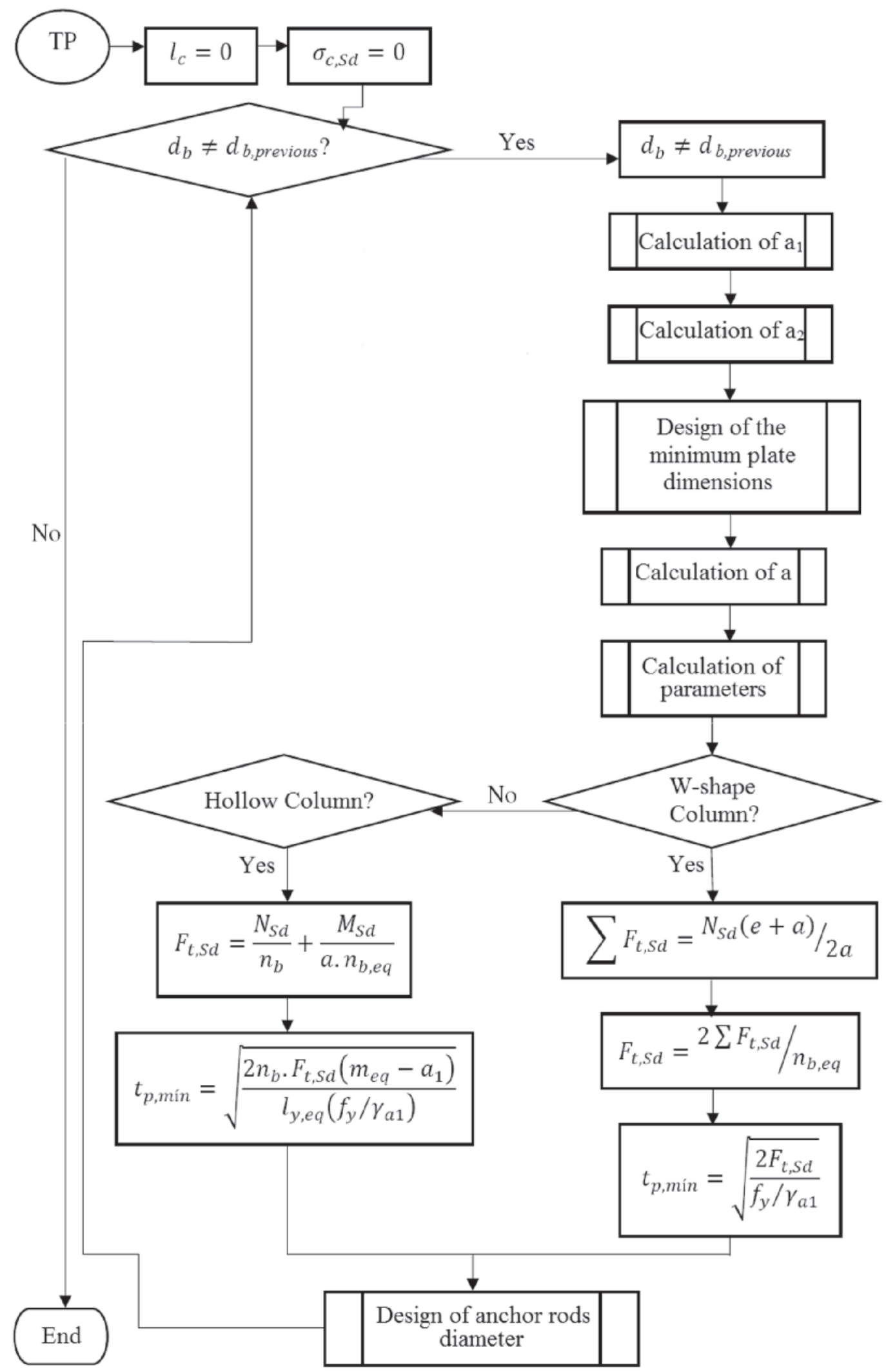

Figure 9

Flowchart of bases subject to tensile force with small moment 
The software input data are:

- The geometry of the base plate (base type: in Figure 10, (a) to (e) must be selected);

- Dimensions of the W-shape or hollow column (the user can choose between the preexisting columns or input the dimensions, Figure 11);

- Internal forces, Figure 12;

- Type of shear element: shear lug or anchor rods, Figure 12;

- The position of the contact plane between the plate and the concrete surface: under (embedded plates), coincident (plates

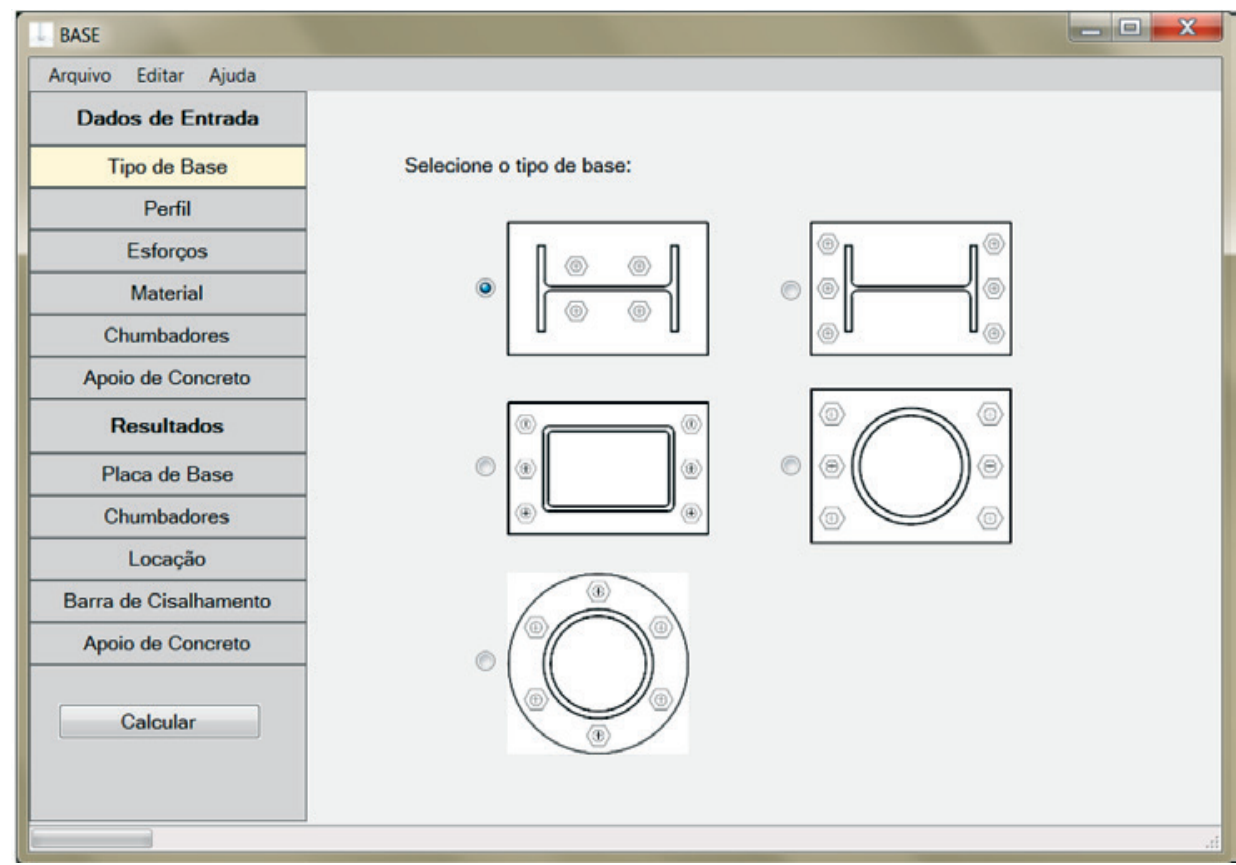

\section{Figure 10}

Input data window of base type definition

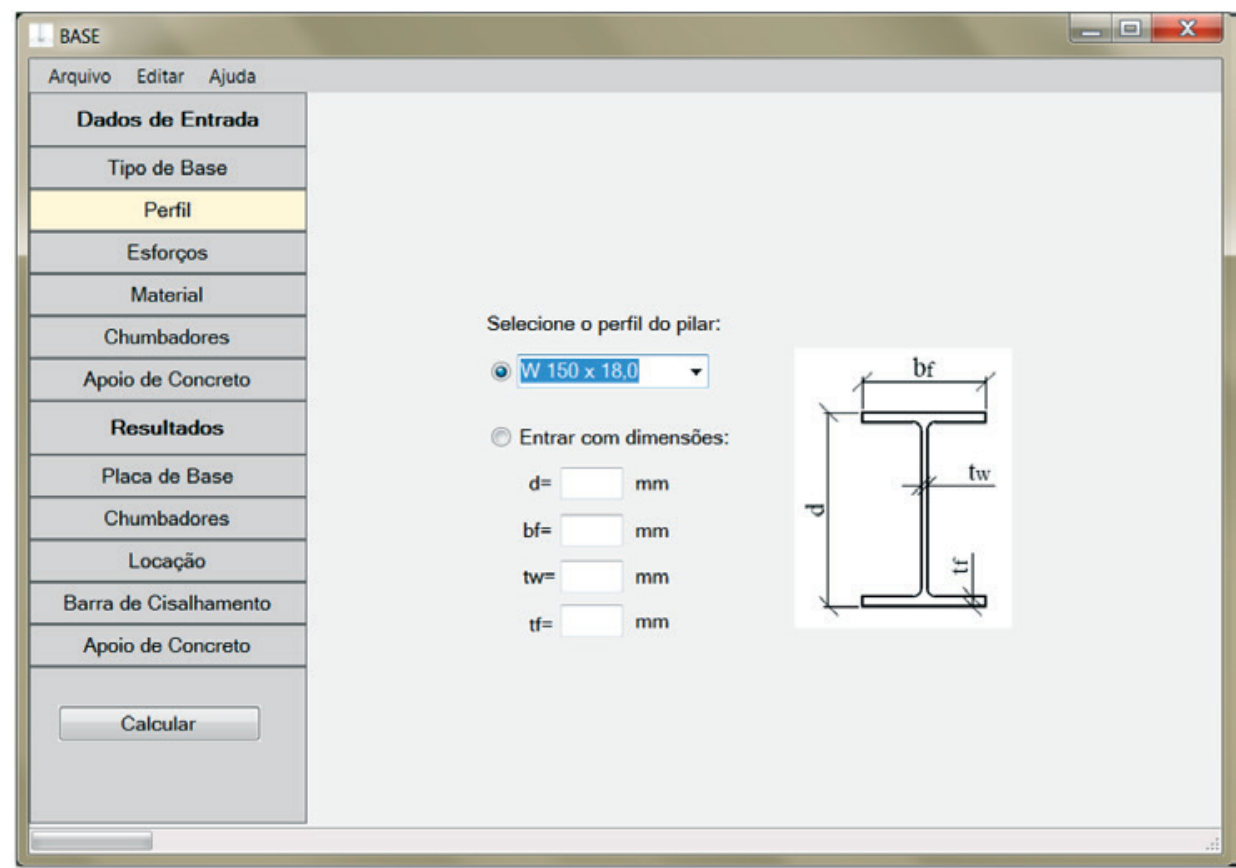

\section{Figure 11}

Input data window of column definition 
placed directly at footing) or above the concrete surface (plates placed upon grout), Figure 12;

- The steel yield limit of the base plate and shear lug, the steel tensile strength of the anchor rods and the concrete compressive strength (the user can choose between preexisting materials or input new properties);

- The number of anchor rods at the plate and the type of anchor rod (with $90^{\circ}$ elbow or with anchor plate at the end);

- The consideration of the confinement effect on concrete: ignore the effect, dimension the concrete area considering the

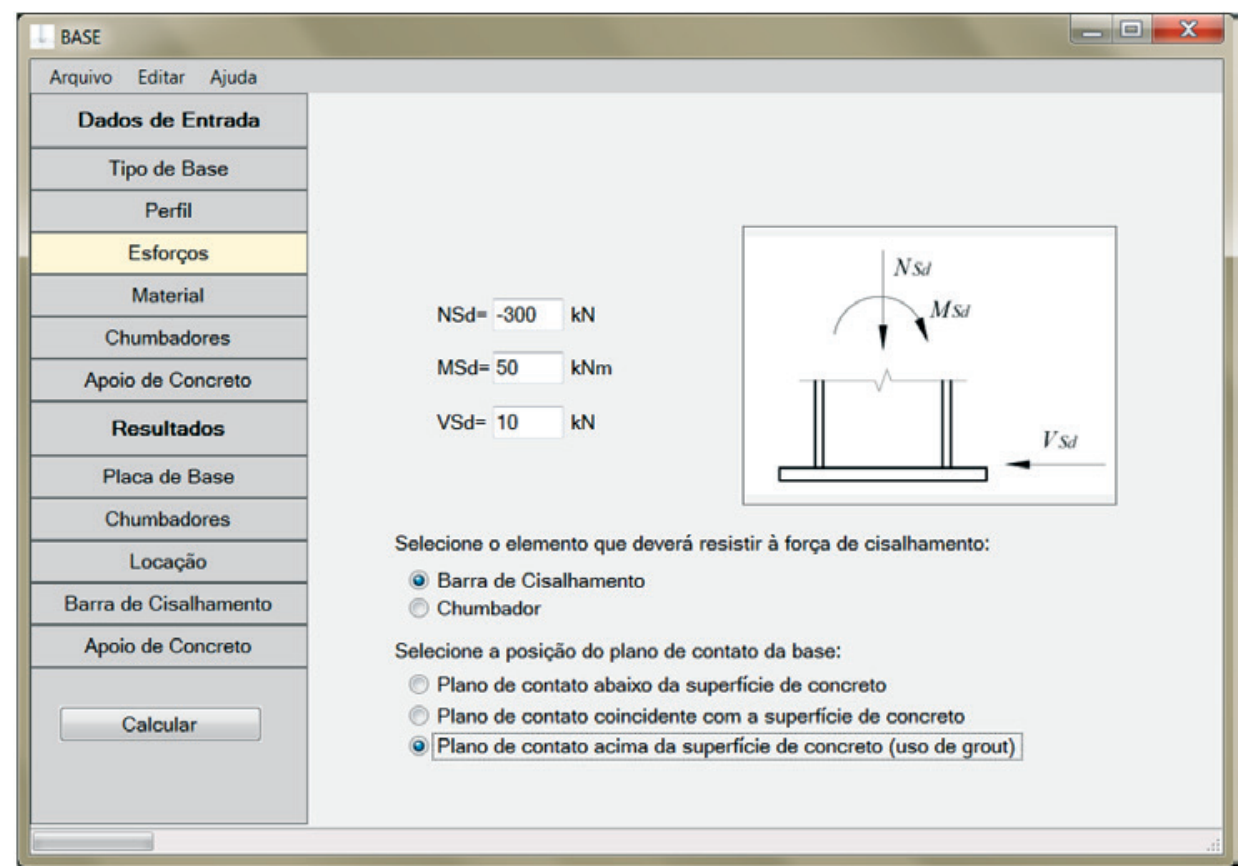

Figure 12

Input data window of forces

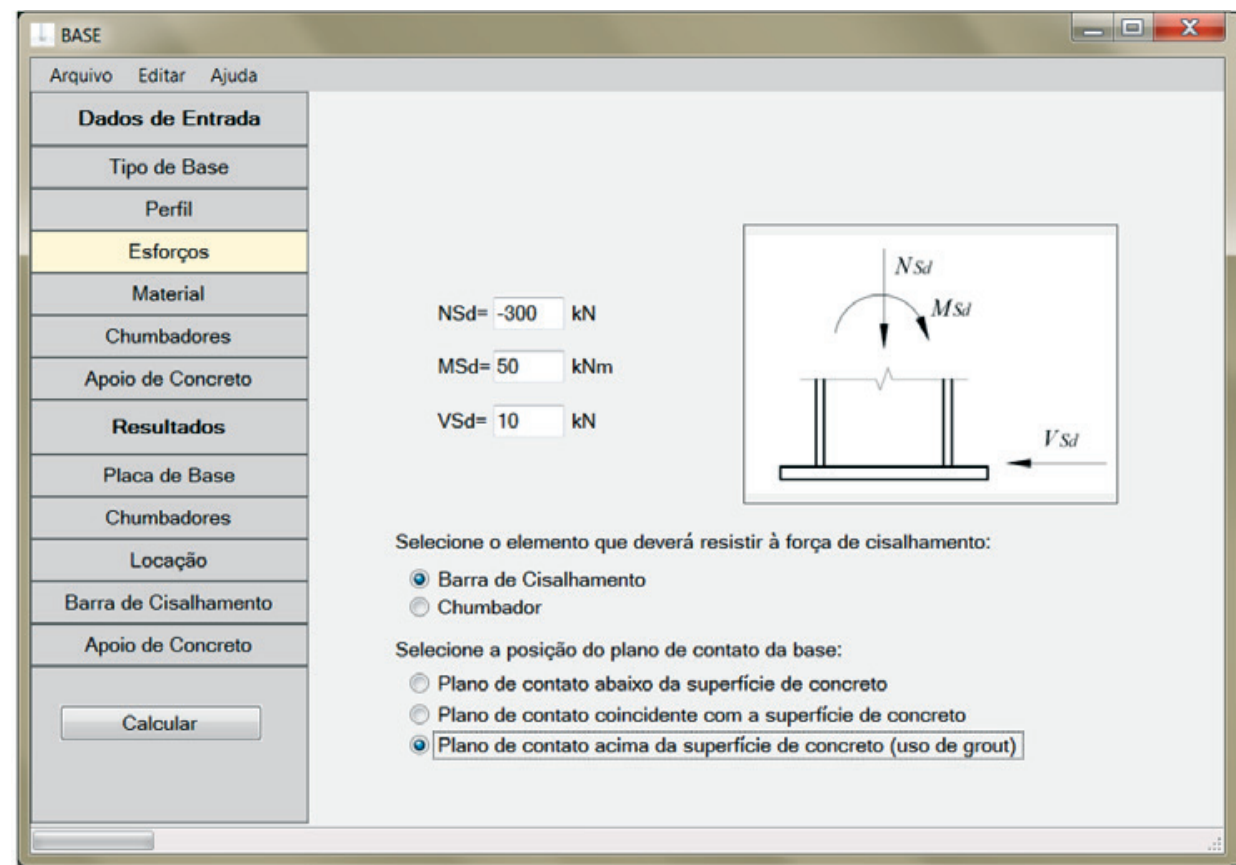

Figure 13

Input data window of concrete footing surface 
maximum confinement effect or enter the preexisting dimensions of the concrete area, Figure 13.

The software output data are:

- Plate dimensions (thickness, width and length) and its weight in kilograms;

- Anchor rods length and minimum commercial diameter;

- Shear lug dimensions;

- The distances from the center of the anchor rod to the edge of the plate and to the center of the nearest anchor rod, Figure 14;

- The minimum horizontal dimensions of the concrete footing (when the user chooses to dimension the concrete area).

The software output dimensions are the minimum values determined for the elements to have a safe design. Therefore, the designer can adopt larger dimensions.

With the development of this software, the authors intend to provide the academic community a toll of easy use and in accordance with Brazilian design standards prescriptions which also enables comparison between the uniform and triangular bearing pressure hypotheses.

\subsection{Software limitations}

The Brazilian standard NBR 16239:2013 [3] restricts the number of anchor rods at hollow columns bases with rectangular plates in four to eight and, for circular plates, between eight and twelve anchor rods. Besides that, the largest dimension of the column transversal section is also limited in $510 \mathrm{~mm}$. Because the software uses the design procedure of NBR 16239:2013 [3], it does not designs hollow column bases that are out of these specifications. Others limitations of the software are:

- Does not design base plates with stiffeners welded to the plate and the column;
Does not design base plates with moment in the direction of the smaller inertia axis of the column;

- Considers the columns centered in the base plates and the base plates centered in the concrete footing;

- Does not consider the confinement effect for concrete strength determination in plates compressed with moment and for shear lugs design;

- Does not consider bending in anchor rods when there are washers welded to the base plate;

- In case of tensile force at the anchor rods in the bases type (b), (c) and (d) of Figure 2, it is not verified if the lines of distribution of tension in $45^{\circ}$ starting in the center of the anchor rod intercept the edge of the base plate;

- The software does not accept null axial force;

- The software dimensions just two types of anchor rods: L-bolts and stud-welded plates (or headed bolts).

\subsection{Software presentation}

The access to the program windows is done through the input and output data bar located to the left of the screens. The user should enter the data in the input data tabs (tabs: "Tipo de Base", "Perfil", "Esforços", "Material", "Chumbadores" and "Apoio de Concreto") and, after calculating the base, the user can view the results on the output data tabs (tabs: "Placa de Base", "Chumbadores", "Locação", "Barra de Cisalhamento" e "Apoio de Concreto"). To calculate the base, the user must click the "Calculate" button at the bottom of the data bar and select which calculation method will be used (uniform contact pressure distribution or triangular pressure distribution). As illustration, Figures 10 to 14 show some of the program windows. The program has a database with $\mathrm{W}$-shape profiles produced by

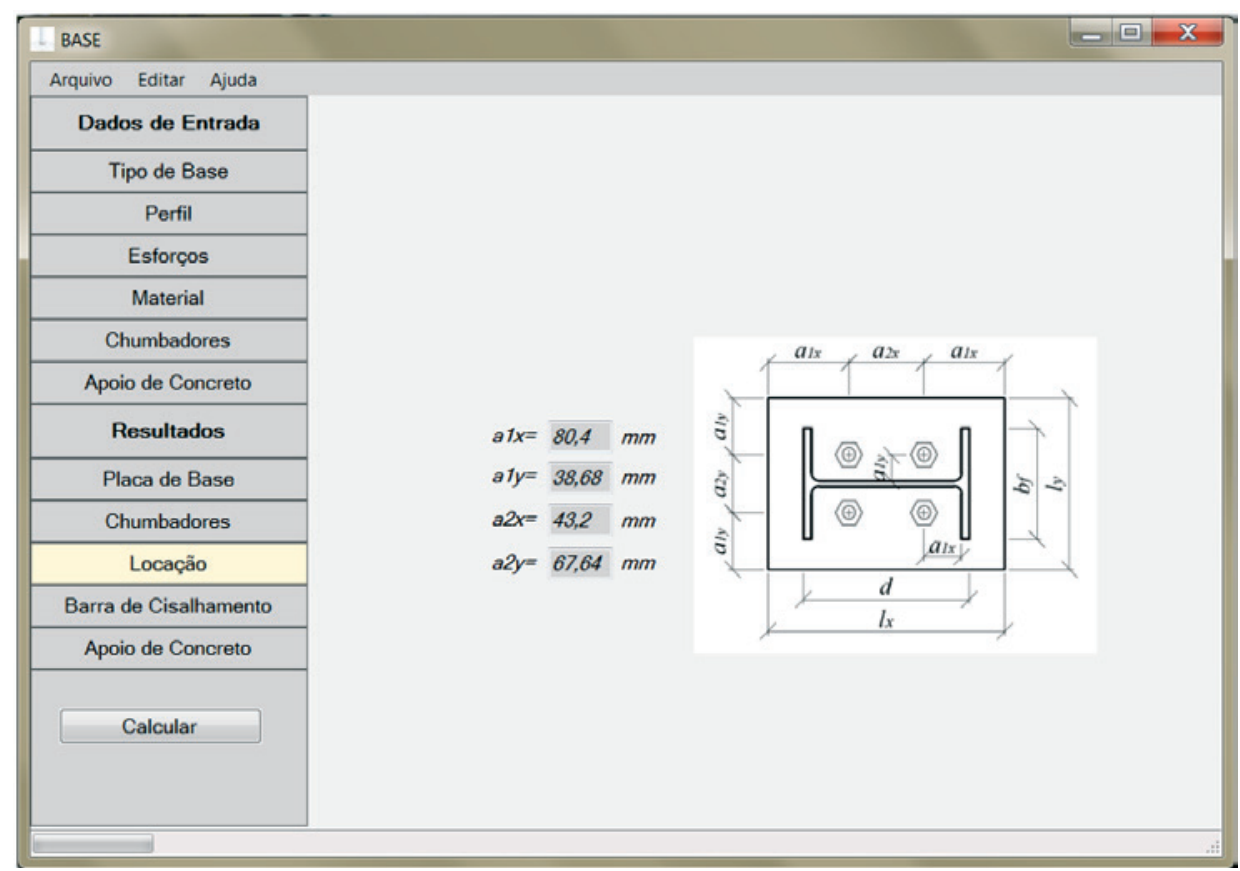

Figure 14

Output data window of anchor rods locations 
Gerdau Açominas and with the hollow profiles produced by $V$ \& $M$ do Brasil, only needed to select the profile designation. The diameter of the anchor bolt is calculated by the software and indicated in commercial dimensions, with a minimum limit of $16 \mathrm{~mm}$.

In the "Apoio de Concreto" window (Figure 13), the user decides whether or not to consider the confinement effect on concrete. If the user wants to consider, the user should indicate whether there are already defined dimensions for the concrete area that will receive the base plate or if the user wants the software to calculate it. If the user wants the program to dimension the concrete area, an area is going to be determined in which the confinement effect provides a maximum concrete strength.

\subsection{Software validation}

In order to validate all the design procedures relative to all different force requirement cases addressed in item 2 , it was decided to solve examples manually and to compare them with the results of the software BASE. This choice is justified due to a lack of examples of column base design in the national literature. In addition, the use of examples from the international literature would not be ideal since there would be divergences in results due to differences in safety coefficients, design distances and profiles used in columns. In order to elaborate the manually solved examples, the loadings were chosen so that an example for each case type was solved, that is, examples of compression with small and large moment and tensile with small and large moment were solved considering both uniform and triangular contact pressure distribution hypotheses, according to Table 1 . All tests were solved for W-shape column bases, with the parameters related to the fixed materials: ASTM A36 steel for base plates, anchor rods and shear lugs (when used) and C20 concrete. The examples considered four anchor rods per base plate for all validation tests.

Table 1 shows the solved tests with their respective input data. The first column refers to the base types according to Figure 2. The "Effect of Containment" column informs the consideration of the effect of confinement: "não se aplica" (when it is not a case of pure compression), "sim" (when the effect is considered and the dimensions of the concrete element are provided by the user), "Ignorado" (when no effect is desired) and "Dimensionar A2" (when user wishes to consider the effect of confinement and do not has pre-defined concrete element dimensions).

After the resolution of the tests in the software BASE, it was observed that there were practically no deviations between the manual and program results (the results of the tests can be observed in Table 1). However, small deviations, of the order of $0.01 \%$, can be expected due to rounding of the manual calculations. Therefore, the program was considered validated for I Profile Baseplates.

\section{Table 1}

Input and output data of the tests used for the software validation

\begin{tabular}{|c|c|c|c|c|c|c|c|c|c|c|c|}
\hline \multicolumn{7}{|c|}{ Input data } & \multicolumn{5}{|c|}{ Output data } \\
\hline \multirow{2}{*}{ Tests } & \multirow{2}{*}{$\begin{array}{l}\text { Type } \\
\text { of base }\end{array}$} & \multirow{2}{*}{ Column } & \multicolumn{3}{|c|}{ Request } & \multirow{2}{*}{$\begin{array}{c}\text { Confinement } \\
\text { effect }\end{array}$} & \multicolumn{3}{|c|}{ Base plates } & \multirow{2}{*}{$\begin{array}{c}\text { Anchor } \\
\text { rods }\end{array}$} & \multirow{2}{*}{ Classification } \\
\hline & & & $\mathrm{N}_{\mathrm{Sd}}$ & $M_{S d}$ & $\mathrm{~V}_{\mathrm{Sd}}$ & & $\mathrm{I}_{\mathrm{x}}$ & $I_{y}$ & $t_{p}$ & & \\
\hline Test 1 & (a) & W250 x 73.0 & -300 & 0 & 0 & Do not apply & 253 & 254 & 25.7 & 22.0 & Tension \\
\hline Test $2^{(1)}$ & (b) & W150 x 18.0 & -300 & 10 & 0 & Do not apply & 333 & 210 & 29.0 & 24.0 & Tension + small moment \\
\hline Test $3^{(1)}$ & (b) & W150 x 18.0 & -300 & 100 & 0 & Do not apply & 527 & 437 & 35.9 & 36.0 & Tension + large moment \\
\hline Test 4 & (a) & W200 x 15.0 & 300 & 0 & 0 & Ignored & 227 & 130 & 10.6 & 16.0 & Compression \\
\hline Test 5 & (a) & W200 $\times 15.0$ & 300 & 0 & 0 & Dimension $\mathrm{A}_{2}$ & 200 & 128 & 11.4 & 16.0 & Compression \\
\hline Test 6 (2) & (a) & W200 x 15.0 & 300 & 0 & 0 & Yes & 200 & 128 & 11.4 & 16.0 & Compression \\
\hline Test 7 (1) & (b) & W150 x 18.0 & 300 & 5 & 0 & Do not apply & 277 & 142 & 18.2 & 16.0 & Compression + small moment \\
\hline Test $8^{(1)}$ & (b) & W150 x 18.0 & 300 & 7 & 0 & Do not apply & 277 & 142 & 18.7 & 16.0 & Compression + small moment \\
\hline Test 9 (1) & (b) & W150 x18.0 & 300 & 50 & 0 & Do not apply & 366 & 242 & 33.1 & 16.0 & Compression + large moment \\
\hline Test $10^{(3)}$ & (a) & W200 $\times 15.0$ & 300 & 0 & 100 & Ignored & 227 & 130 & 10.6 & 16.0 & Compression + shear \\
\hline Test $11{ }^{(4)}$ & (a) & W200 x 15.0 & -150 & 0 & 50 & Do not apply & 200 & 142 & 18.2 & 19.0 & Compression + shear \\
\hline Test $12^{(5)}$ & (b) & W150 x 18.0 & 300 & 10 & 0 & Do not apply & 300 & 165 & 22.3 & 16.0 & Compression + small moment \\
\hline Test 13 ${ }^{(5)}$ & (b) & W150 x 18.0 & 300 & 50 & 0 & Do not apply & 396 & 261 & 34.8 & 19.0 & Compression + large moment \\
\hline Test $14^{(5)}$ & (b) & W150 x 18.0 & -300 & 10 & 0 & Do not apply & 333 & 210 & 29.0 & 24.0 & Tension + small moment \\
\hline Test $15^{(5)}$ & (b) & W150 x 18.0 & -300 & 100 & 0 & Do not apply & 483 & 385 & 39.3 & 38.0 & Tension + large moment \\
\hline
\end{tabular}




\section{Results and discussions}

Two hundred W-shape column bases were designed in the developed software, the first one hundred bases subject to tensile force with moment and the last one hundred to compression force with moment. The goal was to compare the results of the designed base plates subject to moment considering both hypotheses of contact pressure distribution, uniform and triangular

All calculated bases had the following common features: base type (b) of Figure 2, ASTM A36 steel for base plates and anchor bolts, C20 concrete and four anchor rods per plate. Given the large amount of information about the two hundred column bases calculated, it is not possible to present all input and output data. Therefore, in Table 2 were selected some of the bases designed with tensile force with moment and presented their respective results. Analogously, Table 3 shows the input data and results of some of the bases designed with compression and moment. In addition, both tables show the respective percentage differences between

Table 2

Bases designed considering tensile force with moment (sample results)

\begin{tabular}{|c|c|c|c|c|c|c|c|c|c|}
\hline \multicolumn{5}{|c|}{ Input data } & \multicolumn{5}{|c|}{ Results } \\
\hline \multirow{2}{*}{$\mathbf{N}^{\circ}$} & \multirow{2}{*}{ Column } & \multicolumn{2}{|c|}{ Request } & \multirow{2}{*}{ Hypothesis } & \multicolumn{3}{|c|}{ Base plate } & \multicolumn{2}{|c|}{ Anchor rods } \\
\hline & & $\mathrm{N}_{\mathrm{Sd}}$ & $\mathrm{M}_{\mathrm{Sd}}$ & & $I_{x}$ & $\mathrm{I}_{y}$ & $t_{p}$ & $d_{b}$ & $\mathrm{~L}_{c}$ \\
\hline \multirow{3}{*}{1} & \multirow{3}{*}{ W150x13,0 } & \multirow{3}{*}{-25} & \multirow{3}{*}{30} & Uniform & 311 & 192 & 24.24 & 20.0 & 240 \\
\hline & & & & Triangular & 328 & 210 & 23.57 & 20.0 & 240 \\
\hline & & & & Difference (\%) & $-5.47 \%$ & $-9.38 \%$ & $2.76 \%$ & $0.00 \%$ & $0.00 \%$ \\
\hline \multirow{3}{*}{19} & \multirow{3}{*}{ W200x26,6 } & \multirow{3}{*}{-150} & \multirow{3}{*}{40} & Uniform & 420 & 242 & 26.78 & 24.0 & 288 \\
\hline & & & & Triangular & 420 & 242 & 26.82 & 24.0 & 288 \\
\hline & & & & Difference (\%) & $0.00 \%$ & $0.00 \%$ & $-0.15 \%$ & $0.00 \%$ & $0.00 \%$ \\
\hline \multirow{3}{*}{41} & \multirow{3}{*}{$W 250 \times 25,3$} & \multirow{3}{*}{-250} & \multirow{3}{*}{60} & Uniform & 484 & 264 & 33.84 & 30.0 & 360 \\
\hline & & & & Triangular & 484 & 264 & 33.85 & 30.0 & 360 \\
\hline & & & & Difference (\%) & $0.00 \%$ & $0.00 \%$ & $-0.03 \%$ & $0.00 \%$ & $0.00 \%$ \\
\hline \multirow{3}{*}{48} & \multirow{3}{*}{$W 250 \times 25,3$} & \multirow{3}{*}{-300} & \multirow{3}{*}{80} & Uniform & 531 & 317 & 35.65 & 32.0 & 384 \\
\hline & & & & Triangular & 531 & 317 & 35.66 & 32.0 & 384 \\
\hline & & & & Difference (\%) & $0.00 \%$ & $0.00 \%$ & $-0.03 \%$ & $0.00 \%$ & $0.00 \%$ \\
\hline \multirow{3}{*}{52} & \multirow{3}{*}{ W310x21,0 } & \multirow{3}{*}{-200} & \multirow{3}{*}{50} & Uniform & 516 & 242 & 29.94 & 27.0 & 324 \\
\hline & & & & Triangular & 516 & 242 & 29.94 & 27.0 & 324 \\
\hline & & & & Difference (\%) & $0.00 \%$ & $0.00 \%$ & $0.00 \%$ & $0.00 \%$ & $0.00 \%$ \\
\hline & & & & Uniform & 602 & 282 & 34.50 & 30.0 & 360 \\
\hline 60 & W360x57,8 & -200 & 100 & Triangular & 602 & 282 & 34.57 & 30.0 & 360 \\
\hline & & & & Difference (\%) & $0.00 \%$ & $0.00 \%$ & $-0.20 \%$ & $0.00 \%$ & $0.00 \%$ \\
\hline & & & & Uniform & 626 & 264 & 33.73 & 30.0 & 360 \\
\hline 72 & W410x38,8 & -400 & 30 & Triangular & 626 & 264 & 33.73 & 30.0 & 360 \\
\hline & & & & Difference (\%) & $0.00 \%$ & $0.00 \%$ & $0.00 \%$ & $0.00 \%$ & $0.00 \%$ \\
\hline & & & & Uniform & 798 & 317 & 40.04 & 36.0 & 432 \\
\hline 86 & W530x72,8 & -200 & 200 & Triangular & 809 & 333 & 39.10 & 36.0 & 432 \\
\hline & & & & Difference (\%) & $-1.38 \%$ & $-5.05 \%$ & $2.35 \%$ & $0.00 \%$ & $0.00 \%$ \\
\hline & & & & Uniform & 882 & 317 & 41.41 & 36.0 & 432 \\
\hline 97 & W610x113,0 & -400 & 150 & Triangular & 882 & 317 & 41.41 & 36.0 & 432 \\
\hline & & & & Difference (\%) & $0.00 \%$ & $0.00 \%$ & $0.00 \%$ & $0.00 \%$ & $0.00 \%$ \\
\hline & & & & Uniform & 982 & 437 & 55.05 & 50.0 & 600 \\
\hline 100 & W610x113,0 & -1000 & 150 & Triangular & 982 & 437 & 55.05 & 50.0 & 600 \\
\hline & & & & Difference (\%) & $0.00 \%$ & $0.00 \%$ & $0.00 \%$ & $0.00 \%$ & $0.00 \%$ \\
\hline
\end{tabular}


the design considering uniform and triangular bearing pressure distribution hypotheses. Bases subject to shear stress were not designed since the procedure is the same independent of the considered contact stress hypothesis.

Some bases subject to tension with moment did not provide plate thickness $t$ values. It was observed that this situation always occurred for the triangular hypothesis of stress distribution. When analyzing the design of these bases in particular, it was noticed that all these cases were bases with large moment and that the reason why the program did not return values was because the variable $l_{c}$ that represents the bearing length between the plate and the concrete acquired a negative value, which is inconsistent for a distance. This was due to the factor $(e-a)$ used in the calculation of $l$ returning a negative value. These results indicate a failure in the design procedure of bases subject to tensile with large moment and triangular contact pressure distribution, showing that the formulation in this case is only valid when $\mathrm{e}>\mathrm{a}$.

Analyzing the results of the bases subject to compression with mo-

Table 3

Bases designed considering compression force with moment (sample results)

\begin{tabular}{|c|c|c|c|c|c|c|c|c|c|}
\hline \multicolumn{5}{|c|}{ Input data } & \multicolumn{5}{|c|}{ Results } \\
\hline \multirow{2}{*}{$\mathbf{N}^{\circ}$} & \multirow{2}{*}{ Column } & \multicolumn{2}{|c|}{ Request } & \multirow{2}{*}{ Hypothesis } & \multicolumn{3}{|c|}{ Base plate } & \multicolumn{2}{|c|}{ Anchor rods } \\
\hline & & $\mathrm{N}_{\mathrm{Sd}}$ & $\mathrm{M}_{\mathrm{Sd}}$ & & $I_{x}$ & $\mathrm{I}_{y}$ & $t_{p}$ & $d_{b}$ & $\mathrm{~L}_{c}$ \\
\hline \multirow{3}{*}{101} & \multirow{3}{*}{ W150x13,0 } & \multirow{3}{*}{25} & \multirow{3}{*}{30} & Uniform & 311 & 192 & 25.29 & 19.0 & 228 \\
\hline & & & & Triangular & 328 & 210 & 24.59 & 19.0 & 228 \\
\hline & & & & Difference (\%) & $-5.47 \%$ & $-9.38 \%$ & $2.77 \%$ & $0.00 \%$ & $0.00 \%$ \\
\hline \multirow{3}{*}{119} & \multirow{3}{*}{ W200x26,6 } & \multirow{3}{*}{150} & \multirow{3}{*}{40} & Uniform & 357 & 175 & 24.03 & 19.0 & 228 \\
\hline & & & & Triangular & 357 & 182 & 22.75 & 20.0 & 240 \\
\hline & & & & Difference (\%) & $0.00 \%$ & $-4.00 \%$ & $5.33 \%$ & $-5.26 \%$ & $-5.26 \%$ \\
\hline \multirow{3}{*}{141} & \multirow{3}{*}{$W 250 \times 25,3$} & \multirow{3}{*}{250} & \multirow{3}{*}{60} & Uniform & 484 & 264 & 35.71 & 16.0 & 192 \\
\hline & & & & Triangular & 442 & 203 & 28.30 & 20.0 & 240 \\
\hline & & & & Difference (\%) & $8.68 \%$ & $23.11 \%$ & $20.75 \%$ & $-25.00 \%$ & $-25.00 \%$ \\
\hline \multirow{3}{*}{148} & \multirow{3}{*}{ W250x25,3 } & \multirow{3}{*}{300} & \multirow{3}{*}{80} & Uniform & 531 & 317 & 41.51 & 16.0 & 192 \\
\hline & & & & Triangular & 477 & 238 & 33.09 & 22.0 & 264 \\
\hline & & & & Difference (\%) & $10.17 \%$ & $24.92 \%$ & $20.28 \%$ & $-37.50 \%$ & $-37.50 \%$ \\
\hline \multirow{3}{*}{152} & \multirow{3}{*}{ W310x21,0 } & \multirow{3}{*}{200} & \multirow{3}{*}{50} & Uniform & 441 & 164 & 22.95 & 16.0 & 192 \\
\hline & & & & Triangular & 442 & 164 & 22.27 & 19.0 & 228 \\
\hline & & & & Difference (\%) & $-0.23 \%$ & $0.00 \%$ & $2.96 \%$ & $-18.75 \%$ & $-18.75 \%$ \\
\hline & & & & Uniform & 546 & 219 & 30.85 & 22.0 & 264 \\
\hline 160 & W360x57,8 & 200 & 100 & Triangular & 585 & 264 & 33.56 & 20.0 & 240 \\
\hline & & & & Difference (\%) & $-7.14 \%$ & $-20.55 \%$ & $-8.78 \%$ & $9.09 \%$ & $9.09 \%$ \\
\hline & & & & Uniform & 523 & 165 & 17.21 & 16.0 & 192 \\
\hline 172 & W410×38,8 & 400 & 30 & Triangular & 523 & 165 & 19.40 & 16.0 & 192 \\
\hline & & & & Difference (\%) & $0.00 \%$ & $0.00 \%$ & $-12.73 \%$ & $0.00 \%$ & $0.00 \%$ \\
\hline & & & & Uniform & 751 & 264 & 37.94 & 27.0 & 324 \\
\hline 186 & W530x72,8 & 200 & 200 & Triangular & 798 & 317 & 40.40 & 27.0 & 324 \\
\hline & & & & Difference (\%) & $-6.26 \%$ & $-20.08 \%$ & $-6.48 \%$ & $0.00 \%$ & $0.00 \%$ \\
\hline & & & & Uniform & 732 & 253 & 27.89 & 16.0 & 192 \\
\hline 197 & W610x113,0 & 400 & 150 & Triangular & 746 & 253 & 26.72 & 16.0 & 192 \\
\hline & & & & Difference (\%) & $-1.91 \%$ & $0.00 \%$ & $4.20 \%$ & $0.00 \%$ & $0.00 \%$ \\
\hline & & & & Uniform & 732 & 253 & 26.41 & 16.0 & 192 \\
\hline 200 & W610x113,0 & 1000 & 150 & Triangular & 759 & 280 & 27.28 & 16.0 & 192 \\
\hline & & & & Difference (\%) & $-3.69 \%$ & $-10.67 \%$ & $-3.29 \%$ & $0.00 \%$ & $0.00 \%$ \\
\hline
\end{tabular}




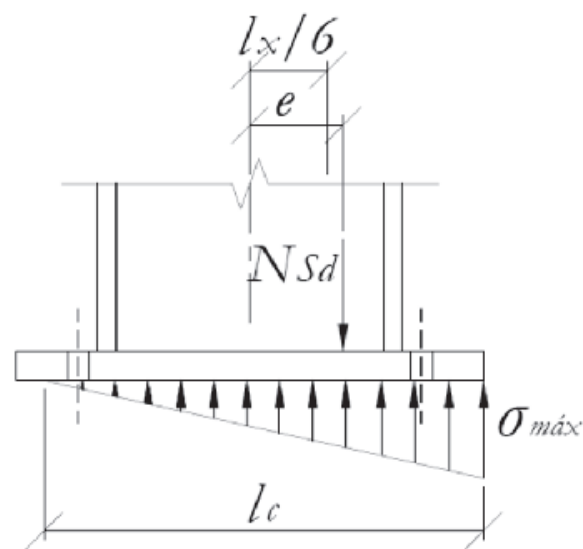

(a) Plate subject to compression

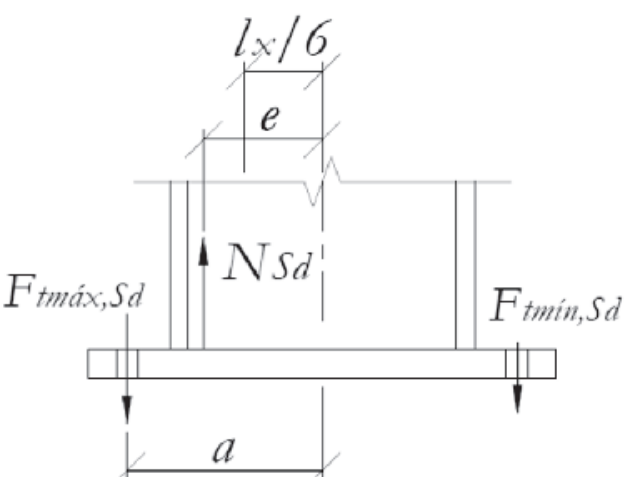

(b) Plate subject to tension

\section{Figure 15}

Bases into eccentricity interval is not covered by triangular contact pressure hypothesis

ment, inconsistencies are also observed in the triangular hypothesis of contact pressure distribution. Although the inconsistencies were not as clearly indicated in the results as in the case of bases subject to tension with moment, it was observed that in some cases, the strength in the anchors acquired a negative value, that is, the anchors were not drawn. This result is inconsistent because the base is considered subject to compression with large moment and the fact that there is no tensile force in the anchor rods makes the base a case of compression with a small moment. The inconsistency was not detected in the thickness results of the base plate, since its value is given by the greater of the values determined by equations (24) and (35), which verify, respectively, the plate bending caused by the tensile force at the anchor rods and the bending at the plate caused by the contact pressure. The negative value of the force on the anchor rods would also influence the design of the anchor rods diameter, but also no inconsistencies were detected, since the program establishes a minimum diameter of $16 \mathrm{~mm}$. According to the above-mentioned inconsistencies, a failure can be observed in the design procedure that considers the hypothesis of triangular contact pressure distribution for both cases of plates subject to tensile with large moment and by compression with large moment. The design procedure that considers triangular contact stress distribution classifies the bases in compressed with large moment or tensioned with large moment if e> $e>l x \mid 6$ for rectangular plates or if $e>l d / 8$ for circular plates. First analyzing the case of compression, classifying a base as compressed with large moment means to consider traction on part of the anchors. Note that the method does not admit that the equivalent eccentricity force may be outside the inertia centroidal kernel without requiring the anchor bolts, as illustrated in Figure 15 (a), creating an interval for which neither the compression with small moment procedure nor the compression with large moment procedure apply. When classifying a base as compressed with large moment, bearing stresses are considered in part of the plate. Note that the triangular distribution method does not admit that the force with equivalent eccentricity may be outside the region of the inertia centroidal kernel without

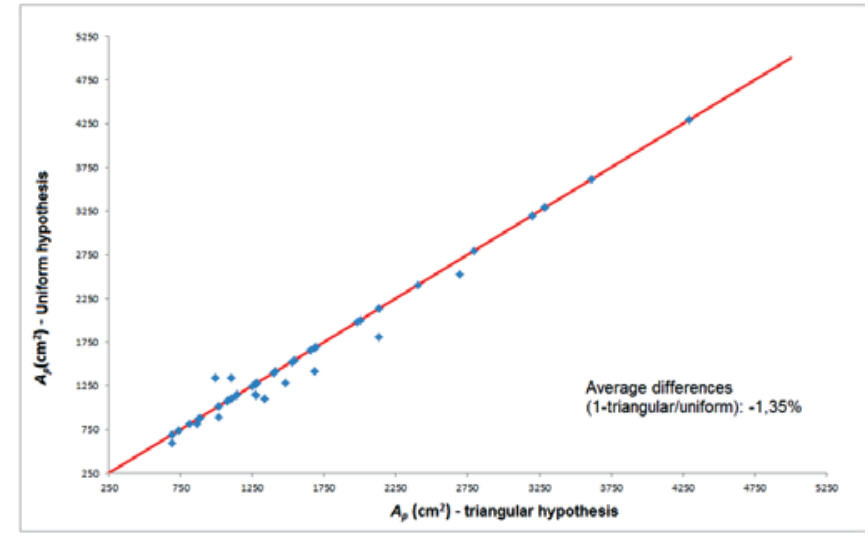

(a) Perfect adjust line - area of the plates subject to tensile force with moment

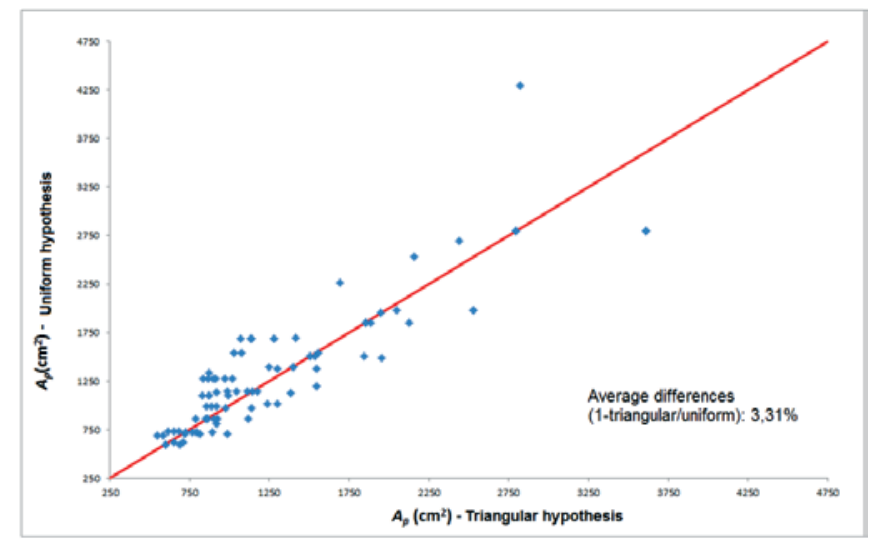

(b) Perfect adjust line - area of the plates subject to compression force with moment

Figure 16

Perfect adjust line graphic for the base plate's area 


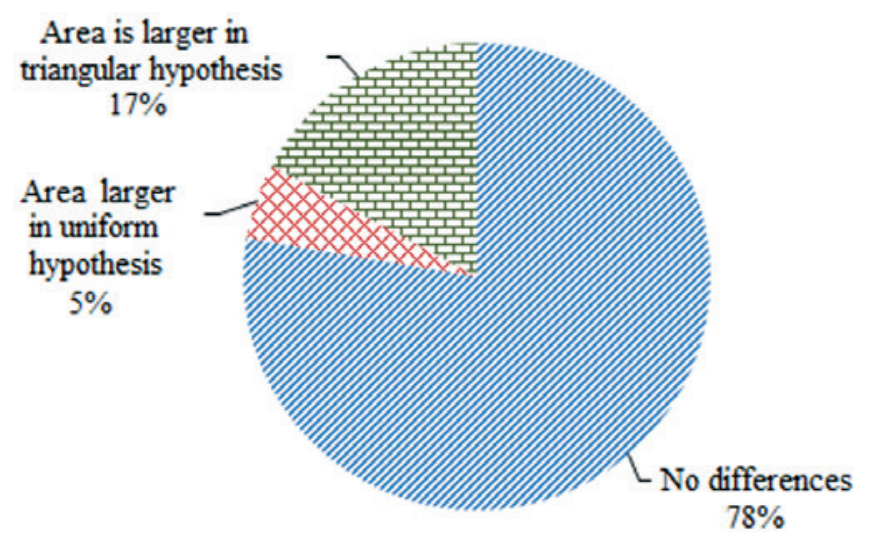

(a) Bases subject to tensile with moment Figure 17

Hypothesis comparison for the design of base plates area

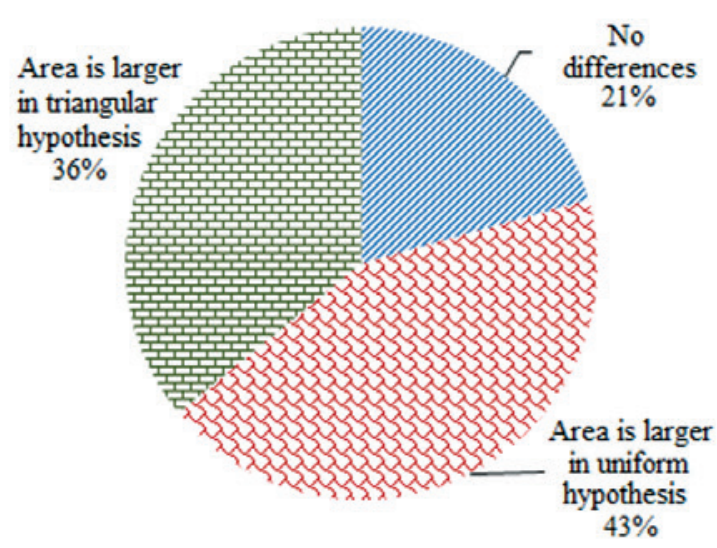

(b) Bases subject to compression with moment bearing pressure at the plate, as shown in Figure 15 (b).

DeWolf and Bicker[7] present a design procedure for compressed bases with moment considering the triangular contact stress distribution. Unlike the procedure of Fisher and Kloiber [2] considered in this text, DeWolf and Bicker [7] consider three magnitudes of moment: small, moderate and large. Such a consideration seems to be more appropriate, since there are actually three different base plate configurations: plate whose triangular bearing pressures exist throughout the base, plate whose contact pressure do not extend all the way, but the anchor rods are not subject to it and plates whose contact pressure exist in only a part and occur tension in the anchor rods. DeWolf and Bicker [7] consider, for rectangular base plates, that if $e \leq 1 x / 6$, the plate is subject tosubject to small moment, if $\mathrm{Ix} / 6<\mathrm{e} \leq \mathrm{Ix} / 2$, to moderate moment and if $\mathrm{e}>\mathrm{Ix} / 2$, to large moment.

However, assuming there is tensile force in the anchors as soon as $\mathrm{e}>\mathrm{Ix} / 2$, it is also an approximation. At first, it seems more appropriate to consider the three cases of magnitude of moment, but to impose as limit between plates of moderate and large

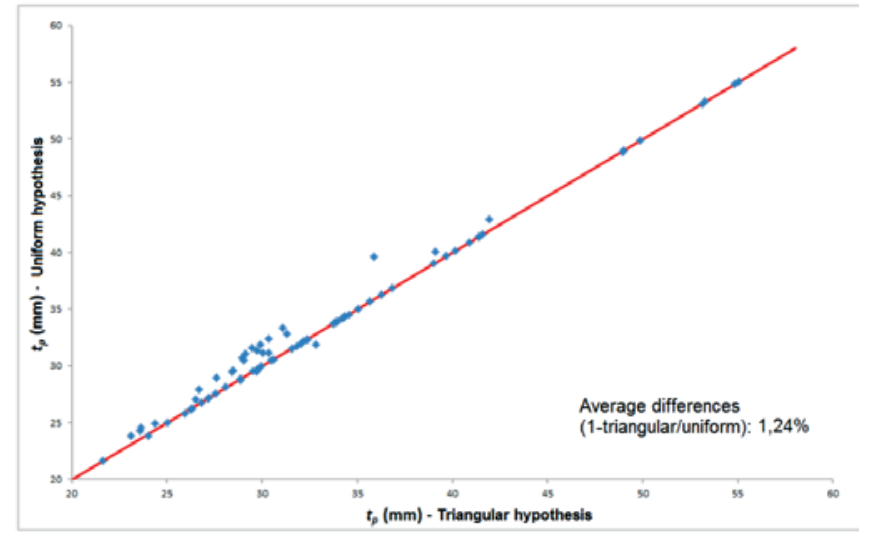

(a) Perfect adjust line - thickness of the plates subject to tensile force with moment moment, an eccentricity that is related to the resistant contact stress of calculation of the concrete, as is done in the method that considers the uniform bearing pressure distribution. In this way, the plate would be subject to a large moment only when the contact pressure on the concrete calculation reached the value of the calculation strength, requiring the anchors to maintain the balance of the base plate.

In order to compare the design hypotheses, perfect fit line plots were drawn, Figures 16 to 18 , contemplating the analysis of the dimensions of the base plates by means of their results for area and thickness, and of the anchors by means of their diameter. The percentage difference averages indicated in the plots is given in relation to the dimensions obtained by the uniform hypothesis. That it, if the average is positive, it means that the uniform hypothesis presented a value greater than that of the linear hypothesis, and vice versa. The bases that had their results considered inconsistent were disregarded. Thus, of the 100 bases subject to tensile force with moment that were processed by the software, 76 were analyzed and of the 100 subject to compression with moment, 92 were analyzed.

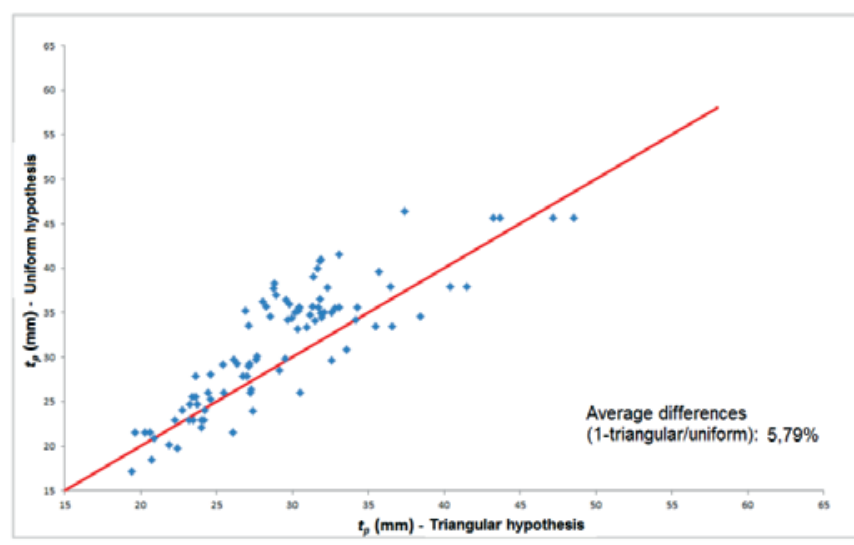

(b) Perfect adjust line - thickness of the plates subject to compression force with moment

\section{Figure 18}

Perfect adjust line graphic for the base plate's thickness 

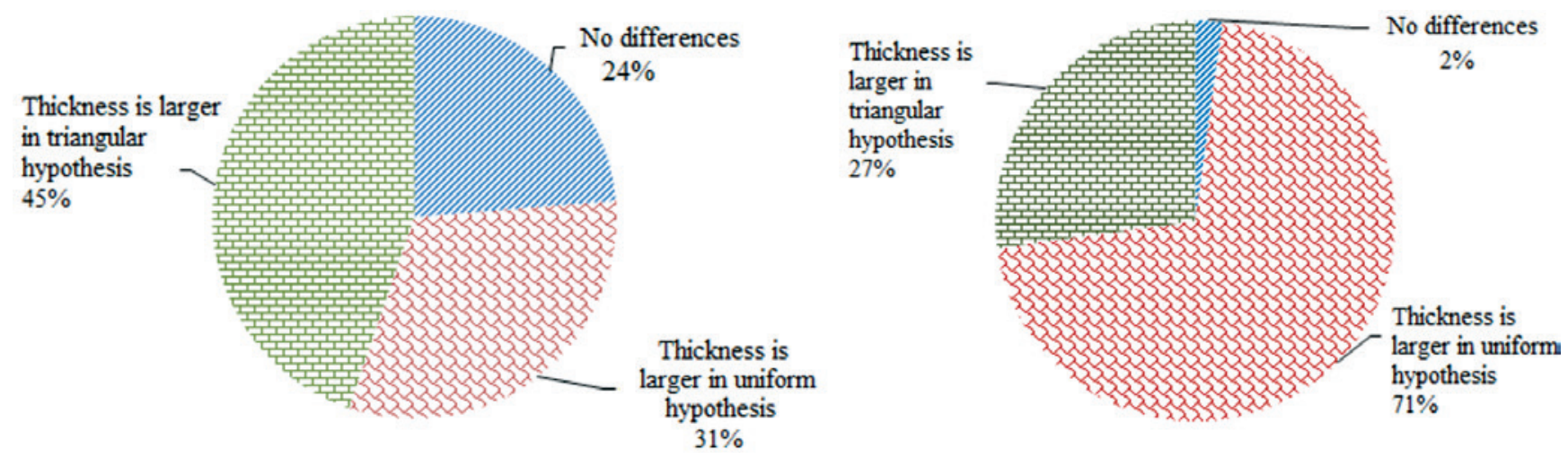

\section{Figure 19}

Hypothesis comparison for the design of base plates thickness

Analyzing the plots of Figure 16 about the area of the base plates, it can be seen that the bases subject to tensile force and moment present a smaller dispersion in the area value. That is, the hypotheses, uniform and linear, give results closer to those observed in the moment compressed bases. This is because, in bases with tensile force, there is only a difference between the methodologies when there are bearing pressures between the plate and the concrete (bases with tension and large moment). In the compressed bases, there are contact stresses in both cases, compressed bases with small moment and with large moment. In the case of the bases with tension and moment, the triangular hypothesis guaranteed a larger area with an average percentage difference of $-1.35 \%$. In the case of compressed bases with moment, the uniform hypothesis guaranteed larger area with an average percentage equal to $3.31 \%$.

Analyzing the case of bases with tension force and moment, in Figure 17 , it is noted that in $78 \%$ of the bases, there was no difference between the methods in the value of the calculated areas, and that is why a large part of the points in Figure 16 (a) are above the perfect fit line and also possibly there are overlapping points with the same area value. In the case of compressed bases with moment, only $21 \%$ of the bases (Figure 17 ) presented the same area value in both methods, so fewer points are on the perfect fit line, Figure 16 (b). The triangular hypothesis guaranteed a larger area (17\% of the bases) for the traction bases if, in the case of compressed bases, the uniform hypothesis guaranteed a larger area ( $43 \%$ of bases).

Figure 18 analyzes the thickness of the base plate plots, in both cases, tensioned and compressed with moment. The hypothesis of uniform distribution provided greater value for the thickness of the base plates, with the average of the larger percentage differences in the bases compressed, equal to $5.79 \%$ against $1.24 \%$ in the bases with tension. Therefore, there was also greater dispersion among the methodologies in the compacted bases with moment. When analyzing Figure 19 , it can be seen that in only $24 \%$ of the bases with tensile force and in $2 \%$ of the compressed bases, the two methodologies provided identical results. The triangular hypothesis guaranteed a greater thickness in $45 \%$ of the bases with tensile and, in the case of compressed bases, the uniform hypothesis guaranteed a greater thickness in $71 \%$ of the bases.

Analyzing the plots of Figure 20, about the diameter of the anchors, it can be noted that there are few points in these plots because the calculated diameters are presented in commercial

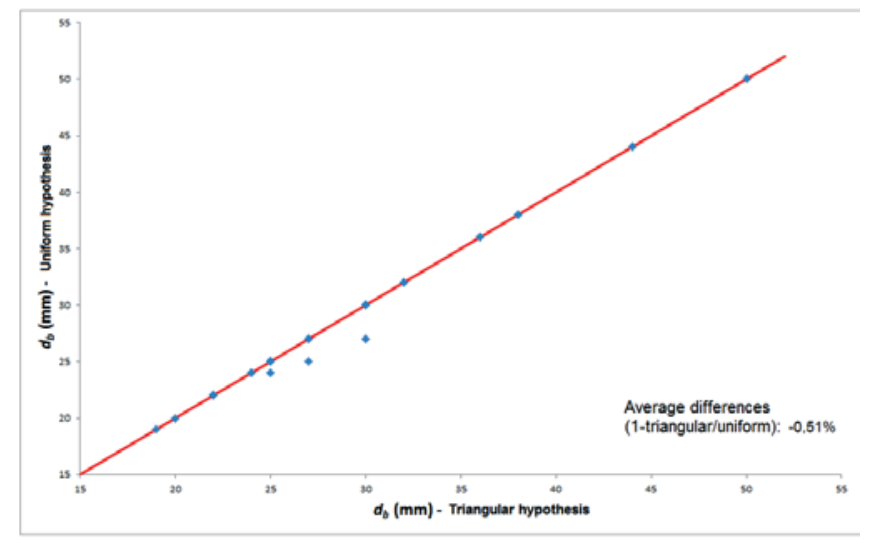

(a) Perfect adjust line - anchor rods diameter of bases subject to tensile with moment

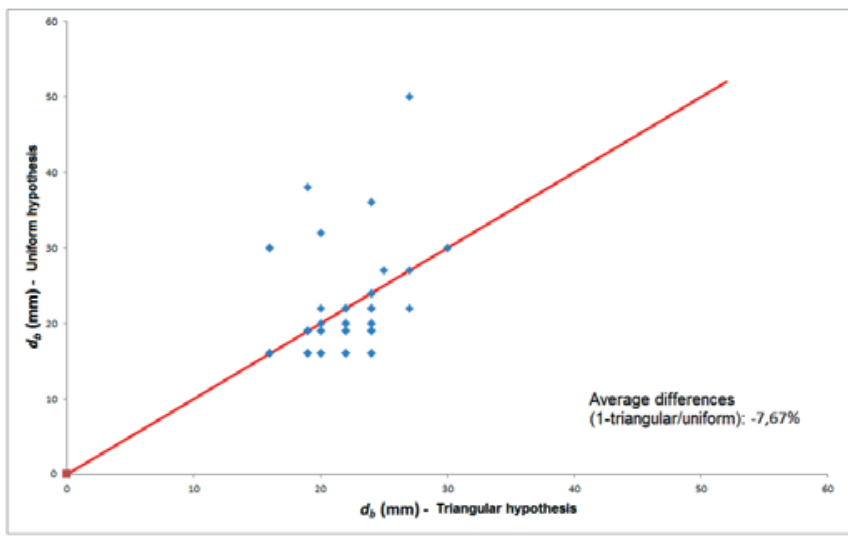

(b) Perfect adjust line - anchor rods diameter of bases subject to compression with moment

Figure 20

Perfect adjust line graphic for the anchor rods diameter 


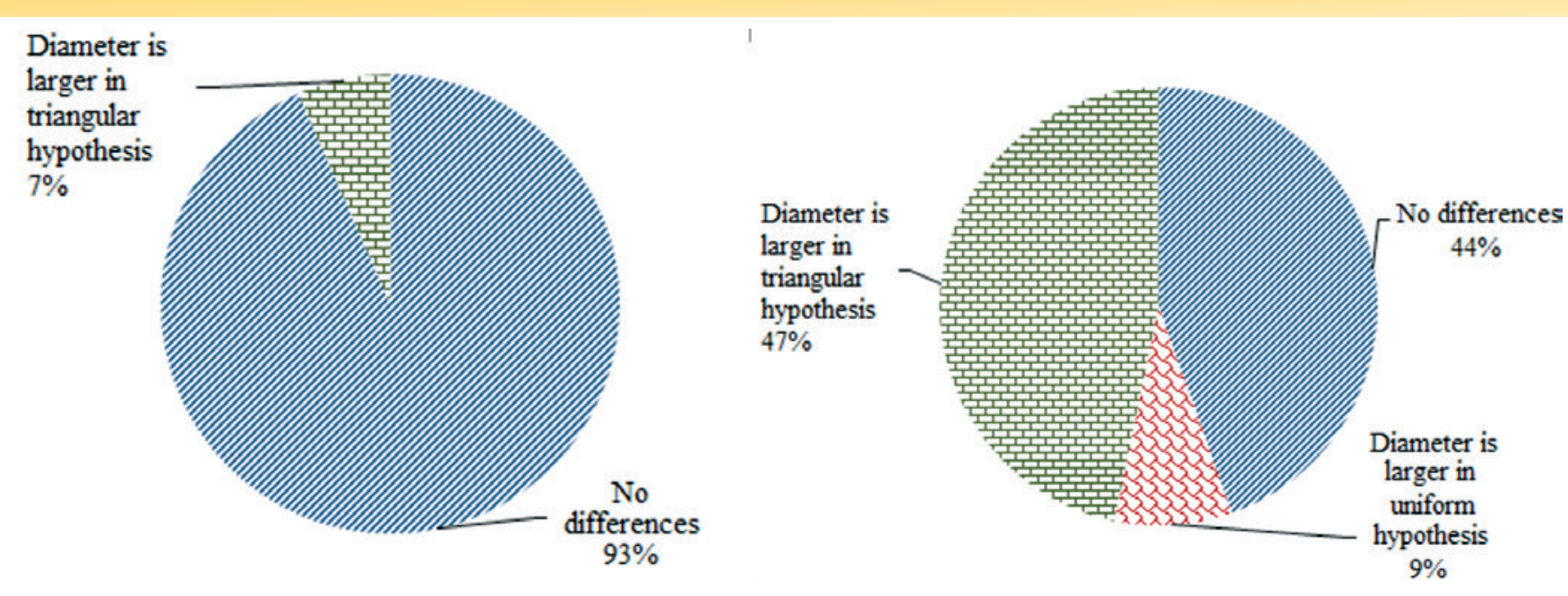

Figure 21

Hypothesis comparison for the design of anchor rods

dimensions, which means that there are overlapping points, one above the other. For the bases with tensile force and moment, there was practically no difference between the methods, the average percentage differences was only $-0.51 \%$. The graph of Figure 21 shows that in $93 \%$ of the bases with tensile force and moment there was no difference between the methodologies, however, in the $7 \%$ in which there was, a larger diameter was noticed for the linear method. For the moment compressed bases, the triangular hypothesis guaranteed a greater diameter of the anchor rods: the average of the percentage differences was $-7.67 \%$ and in $47 \%$ of the compressed bases the triangular hypothesis provided a higher result. In $45 \%$ of the compressed bases, there was no difference between the methodologies.

Fisher and Kloiber [2] said that the use of the triangular bearing pressure distribution method provides thicker base plates and smaller anchors than the uniform method. However, the results obtained when scaling bases in the program showed the exact opposite: for the linear stress distribution method, the plates presented smaller dimensions and the anchor rods, bigger in relation to the uniform bearing distribution method.

\section{Conclusions}

In this study, a software called BASE for the design of steel column bases was developed which uses two different design methodologies about the consideration of the contact pressure distribution, uniform and triangular. This software has been duly validated by a considerable number of manually solved examples for the various loading cases addressed. The software presented itself as a very useful and versatile tool in the automation of the design of column bases.

The inconsistencies observed in some of the results mentioned in the discussion pointed out an interval between small and large eccentricity, for which the design procedure that considers the triangular stress distribution is not appropriate.

Comparing the two hypotheses of stress distribution, the results showed less dispersion in the cases of bases with tension and moment, and the percentage difference average of $-1.35 \%$ and $1.24 \%$ for the area and thickness of the plate, respectively, and $-0.51 \%$ for the diameter of the anchor rods. This lower dispersion occurred because the procedures for calculating these bases differ only in the case of large eccentricity, whereas in the bases compressed with moment, the procedures differ for both cases, that is, small and large eccentricity. The moment compressed bases presented the highest average of the percentage differences between the hypotheses, being $3.31 \%$ for the area and $5.79 \%$ for the thickness of the base plates, and $-7.67 \%$ for the diameter of the anchor rods. The existence of an interval for which the triangular bearing pressure distribution is not appropriate together with the low percentage difference average in the interval where the two hypotheses were compared makes the hypothesis of uniform contact stress distribution the best approximation to be used in the design of steel column bases.

\section{Aknowledgements}

The authors would like to thank CNPq, FAPES, and PPGEC/UFES for the support for the realization of this research.

\section{Referências bibliográficas}

[1] ASSOCIAÇÃO BRASILEIRA DE NORMAS TÉCNICAS. NBR 8800: Projeto de estruturas de aço e de estruturas mistas de aço e concreto de edifícios. Rio de Janeiro, 2008.

[2] FISHER, J.M; KLOIBER, L.A. Steel design guide 1: Base plate and anchor rod design. 2. ed. Chicago: American Institute of Steel Construction, 2006.

[3] ASSOCIAÇÃO BRASILEIRA DE NORMAS TÉCNICAS. NBR 16239: projeto de estruturas de aço e de estruturas mistas de aço e concreto de edificações com perfis tubulares. Rio de Janeiro, 2013.

[4] BELLEI, I. H. Interfaces aço-concreto.Rio de Janeiro: 2006.

[5] BAIÃO FILHO \& SILVA, 2006. Ligações para Estruturas de Aço. Guia Prático para Estruturas com Perfis Laminados. $3^{a}$ Ed. São Paulo: GERDAU Açominas.

[6] VISUAL BASIC 2010 EXPRESS, Microsoft Visual Studio 2010.

[7] DEWOLF, J.T; BICKER, D.T. Steel design guide series 1: Column base plates. Chicago: American Institute of Steel Construction, 1990. 